\title{
Article
}

\section{Azathioprine and 6-mercaptopurine for maintenance of surgically-induced remission in Crohn's disease}

Gordon, Morris, Taylor, kelly, Akobeng, Anthony and Thomas, Adrian

Available at http://clok.uclan.ac.uk/12896/

Gordon, Morris ORCID: 0000-0002-1216-5158, Taylor, kelly, Akobeng, Anthony and Thomas, Adrian (2014) Azathioprine and 6-mercaptopurine for maintenance of surgically-induced remission in Crohn's disease. Cochrane Database of Systematic Reviews (8). CD010233.

It is advisable to refer to the publisher's version if you intend to cite from the work. http://dx.doi.org/10.1002/14651858.CD010233.pub2

For more information about UCLan's research in this area go to http://www.uclan.ac.uk/researchgroups/ and search for <name of research Group>.

For information about Research generally at UCLan please go to http://www.uclan.ac.uk/research/

All outputs in CLoK are protected by Intellectual Property Rights law, including Copyright law. Copyright, IPR and Moral Rights for the works on this site are retained by the individual authors and/or other copyright owners. Terms and conditions for use of this material are defined in the policies page.

\section{CLoK}

Central Lancashire online Knowledge www.clok.uclan.ac.uk

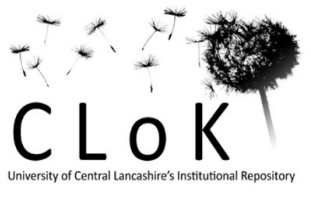




\section{Azathioprine and 6-mercaptopurine for maintenance of surgically-induced remission in Crohn's disease (Review)}

Gordon M, Taylor K, Akobeng AK, Thomas AG

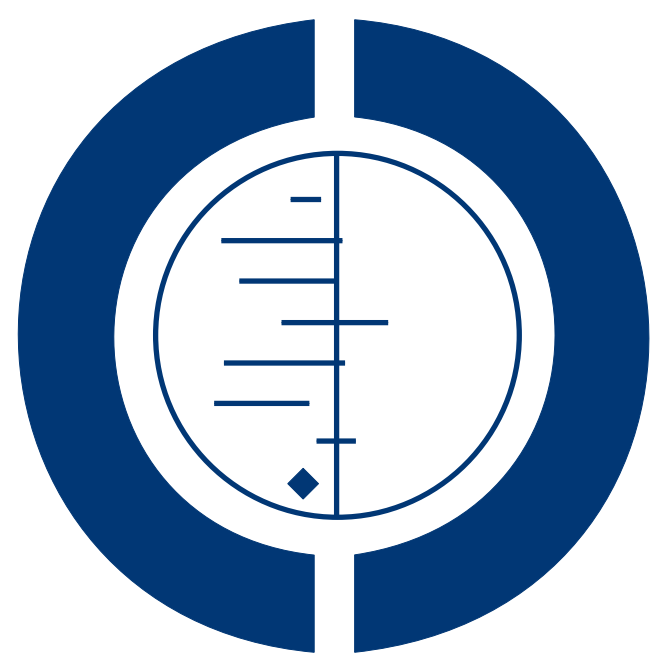

THE COCHRANE
COLLABORATION

This is a reprint of a Cochrane review, prepared and maintained by The Cochrane Collaboration and published in The Cochrane Library 2014, Issue 8

http://www.thecochranelibrary.com

\section{WILEY}

Azathioprine and 6-mercaptopurine for maintenance of surgically-induced remission in Crohn's disease (Review)

Copyright (c) 2014 The Cochrane Collaboration. Published by John Wiley \& Sons, Ltd. 
TABLE OF CONTENTS

HEADER . . . . . . . . . . . . . . . . . . . . . . . . . . . . . . . . . . . . . . . . . . . . .

ABSTRACT . . . . . . . . . . . . . . . . . . . . . . . . . . . . . . . . . . . . . . . . . . . . . . 1

PLAIN LANGUAGE SUMMARY . . . . . . . . . . . . . . . . . . . . . . . . . . . . . . . . . . . . . . . . . . . . .

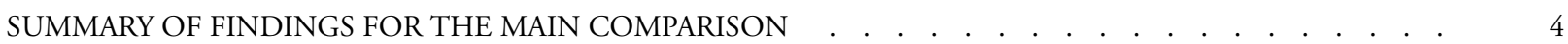

BACKGROUND . . . . . . . . . . . . . . . . . . . . . . . . . . . . . . . . . . . . . . . . . . . 5

OBJECTIVES . . . . . . . . . . . . . . . . . . . . . . . . . . . . . . . . . . . . . . . . . .

METHODS . . . . . . . . . . . . . . . . . . . . . . . . . . . . . . . . . . . . . . . . .

RESULTS . . . . . . . . . . . . . . . . . . . . . . . . . . . . . . . . . . . . . . . . . . . .

Figure 1. . . . . . . . . . . . . . . . . . . . . . . . . . . . . . . . . . . . . . . . . . . . 9

Figure 2. . . . . . . . . . . . . . . . . . . . . . . . . . . . . . . . . . . . . . 11

Figure 3. . . . . . . . . . . . . . . . . . . . . . . . . . . . . . . . . . . . . 12

Figure $4 . \quad$. . . . . . . . . . . . . . . . . . . . . . . . . . . . . . . . . . . . . . . . . . . . . . . .

ADDITIONAL SUMMARY OF FINDINGS . . . . . . . . . . . . . . . . . . . . . . . . . . . . . . . . . .

DISCUSSION . . . . . . . . . . . . . . . . . . . . . . . . . . . . . . . . . . . . . . . . . .

AUTHORS' CONCLUSIONS . . . . . . . . . . . . . . . . . . . . . . . . . . . . . . . . . . . .

ACKNOWLEDGEMENTS . . . . . . . . . . . . . . . . . . . . . . . . . . . . . . . . . . . . . . . .

REFERENCES . . . . . . . . . . . . . . . . . . . . . . . . . . . . . . . . . . . . . . 22

CHARACTERISTICS OF STUDIES . . . . . . . . . . . . . . . . . . . . . . . . . . . . . . . . . . . . . . . .

DATA AND ANALYSES . . . . . . . . . . . . . . . . . . . . . . . . . . . . . . . . . . . . . . . . . . . . . . . . . . . . .

Analysis 1.1. Comparison 1 Azathioprine or 6-mercaptopurine versus placebo, Outcome 1 Clinical relapse (fixed-effect). 33

Analysis 1.2. Comparison 1 Azathioprine or 6-mercaptopurine versus placebo, Outcome 2 Clinical relapse, sensitivity analysis, (random-effects).

Analysis 1.3. Comparison 1 Azathioprine or 6-mercaptopurine versus placebo, Outcome 3 Endoscopic relapse (fixedeffect).

Analysis 1.4. Comparison 1 Azathioprine or 6-mercaptopurine versus placebo, Outcome 4 Adverse events requiring withdrawal (fixed-effect).

Analysis 2.1. Comparison 2 Azathioprine or 6-mercaptopurine versus 5-aminosalicylic acid, Outcome 1 Clinical relapse (fixed-effect).

Analysis 2.2. Comparison 2 Azathioprine or 6-mercaptopurine versus 5-aminosalicylic acid, Outcome 2 Clinical relapse,sensitivity analysis (random-effects).

Analysis 2.3. Comparison 2 Azathioprine or 6-mercaptopurine versus 5-aminosalicylic acid, Outcome 3 Clinical relapse, sensitivity analysis excluding study that enrolled patients with endoscopic recurrence, (fixed-effect).

Analysis 2.4. Comparison 2 Azathioprine or 6-mercaptopurine versus 5-aminosalicylic acid, Outcome 4 Clinical relapse, subgroup analysis by drug type (fixed-effect).

Analysis 2.5. Comparison 2 Azathioprine or 6-mercaptopurine versus 5-aminosalicylic acid, Outcome 5 Clinical relapse, subgroup analysis by length of follow-up.

Analysis 2.6. Comparison 2 Azathioprine or 6-mercaptopurine versus 5-aminosalicylic acid, Outcome 6 Endoscopic relapse (fixed-effect).

Analysis 2.7. Comparison 2 Azathioprine or 6-mercaptopurine versus 5-aminosalicylic acid, Outcome 7 Adverse events (fixed-effect).

Analysis 2.8. Comparison 2 Azathioprine or 6-mercaptopurine versus 5-aminosalicylic acid, Outcome 8 Adverse events requiring withdrawal (fixed-effect).

Analysis 2.9. Comparison 2 Azathioprine or 6-mercaptopurine versus 5-aminosalicylic acid, Outcome 9 Adverse events requiring withdrawal, subgroup analysis by drug type (fixed-effect).

Analysis 2.10. Comparison 2 Azathioprine or 6-mercaptopurine versus 5-aminosalicylic acid, Outcome 10 Serious adverse events (random-effects).

Analysis 3.1. Comparison 3 Azathioprine versus infliximab, Outcome 1 Clinical relapse. . . . . . . . . . . . . . . 44

Analysis 3.2. Comparison 3 Azathioprine versus infliximab, Outcome 2 Endoscopic relapse. . . . . . . . . . . . . 45

Analysis 3.3. Comparison 3 Azathioprine versus infliximab, Outcome 3 Adverse events requiring withdrawal. . . . . 45

Analysis 4.1. Comparison 4 Azathioprine versus adalimumab, Outcome 1 Clinical relapse. . . . . . . . . . . . . . 46

Analysis 4.2. Comparison 4 Azathioprine versus adalimumab, Outcome 2 Endoscopic relapse. . . . . . . . . . . . . 46

Azathioprine and 6-mercaptopurine for maintenance of surgically-induced remission in Crohn's disease (Review)

Copyright (๑) 2014 The Cochrane Collaboration. Published by John Wiley \& Sons, Ltd. 
Analysis 4.3. Comparison 4 Azathioprine versus adalimumab, Outcome 3 Adverse events. . . . . . . . . . . . . 47

Analysis 4.4. Comparison 4 Azathioprine versus adalimumab, Outcome 4 Adverse events requiring withdrawal. $\quad . \quad$. 47

APPENDICES . . . . . . . . . . . . . . . . . . . . . . . . . . . . . . . . . . . . . . . . . . . 447

WHAT'S NEW . . . . . . . . . . . . . . . . . . . . . . . . . . . . . . . . . . . . . . . . . . . .

CONTRIBUTIONS OF AUTHORS . . . . . . . . . . . . . . . . . . . . . . . . . . . . . . . . . . . . . . . . . . . . . . .

DECLARATIONS OF INTEREST . . . . . . . . . . . . . . . . . . . . . . . . . . . . . . . . . . . . 50

DIFFERENCES BETWEEN PROTOCOL AND REVIEW . . . . . . . . . . . . . . . . . . . . . . . . . . 50

INDEX TERMS . . . . . . . . . . . . . . . . . . . . . . . . . . . . . . . . . . . . . . . . . . . . . . . 50 


\title{
[Intervention Review]
}

\section{Azathioprine and 6-mercaptopurine for maintenance of surgically-induced remission in Crohn's disease}

\author{
Morris Gordon ${ }^{1,2}$, Kelly Taylor ${ }^{3}$, Anthony K Akobeng ${ }^{4}$, Adrian G Thomas ${ }^{4}$ \\ ${ }^{1}$ School of Medicine and Dentistry, University of Central Lancashire, Preston, UK. ${ }^{2}$ Department of Child Health, Blackpool Victoria \\ Hospital, Blackpool, UK. ${ }^{3}$ Department of Paediatrics, North Manchester General Hospital, Crumpsall, UK. ${ }^{4}$ Royal Manchester \\ Children's Hospital, Manchester, UK \\ Contact address: Morris Gordon, School of Medicine and Dentistry, University of Central Lancashire, Preston, UK. \\ morris@betterprescribing.com.general@biyeeproperties.com.
}

Editorial group: Cochrane IBD Group.

Publication status and date: New, published in Issue 8, 2014.

Review content assessed as up-to-date: 30 April 2014.

Citation: Gordon M, Taylor K, Akobeng AK, Thomas AG. Azathioprine and 6-mercaptopurine for maintenance of surgically-induced remission in Crohn's disease. Cochrane Database of Systematic Reviews 2014, Issue 8. Art. No.: CD010233. DOI: 10.1002/14651858.CD010233.pub2.

Copyright (C) 2014 The Cochrane Collaboration. Published by John Wiley \& Sons, Ltd.

\begin{abstract}
A B S T R A C T
Background

Crohn's disease (CD) is a chronic relapsing inflammatory condition. Many patients fail to achieve remission with medical management and require surgical interventions. Purine analogues have been used to maintain surgically-induced remission in CD, but the effectiveness of these agents is unclear.
\end{abstract}

\section{Objectives}

The objectives were to evaluate the efficacy and safety of purine analogues for maintenance of surgically-induced remission in CD.

\section{Search methods}

We searched the following databases from inception to 30 April 2014: PubMed, MEDLINE, EMBASE, CENTRAL, and the Cochrane Inflammatory Bowel Disease and Functional Bowel Disorders Group Specialized Trials Register). We also searched the reference lists of all included studies, and contacted personal sources and drug companies to identify additional studies. The searches were not limited by language.

\section{Selection criteria}

Randomised controlled trials (RCTs) that compared purine analogues to placebo or another intervention, with treatment durations of at least six months were considered for inclusion. Participants were patients of any age with CD in remission following surgery.

\section{Data collection and analysis}

Two authors independently assessed trial eligibility and extracted data. Methodological quality was assessed using the Cochrane risk of bias tool. The primary outcome measures were clinical and endoscopic relapse as defined by the primary studies. Secondary outcomes included adverse events, withdrawal due to adverse events and serious adverse events. Data were analysed on an intention-to-treat basis where patients with missing final outcomes were assumed to have relapsed. We calculated the risk ratio (RR) and corresponding $95 \%$ confidence interval $(95 \% \mathrm{CI})$ for dichotomous outcomes. The $\mathrm{Chi}^{2}$ and $\mathrm{I}^{2}$ statistics were used to assess heterogeneity. The overall quality of the evidence supporting the primary outcomes and selected secondary outcomes was assessed using the GRADE criteria.

Azathioprine and 6-mercaptopurine for maintenance of surgically-induced remission in Crohn's disease (Review)

Copyright $\odot 2014$ The Cochrane Collaboration. Published by John Wiley \& Sons, Ltd. 


\section{Main results}

Seven RCTs ( $\mathrm{n}=584$ patients) were included in the review. Three studies compared azathioprine to 5-aminosalicylic acid (5-ASA). One small study compared azathioprine to both 5-ASA and adalimumab. One study compared azathioprine to placebo and another study compared 6-mercaptopurine to 5-ASA and placebo. One small study compared azathioprine to infliximab. Three studies were judged to be at low risk of bias. Four studies were judged to be at high risk of bias due to blinding. The study $(\mathrm{n}=22)$ comparing azathioprine to infliximab found that the effects on the proportion of patients who had a clinical (RR 2.00, 95\% CI 0.21 to 18.98) or endoscopic relapse (RR 4.40, 95\% CI 0.59 to 3.07) were uncertain. One study $(\mathrm{n}=33$ ) found decreased clinical (RR 5.18, 95\% CI 1.35 to 19.83) and endoscopic relapse (RR 10.35, 95\% CI 1.50 to 71.32) rates favouring adalimumab over azathioprine. A pooled analysis of two studies ( $\mathrm{n}=168$ patients) showed decreased clinical relapse rates at one or two years favouring purine analogues over placebo. Fortyeight per cent of patients in the purine analogue group experienced a clinical relapse compared to 63\% of placebo patients (RR 0.74 , $95 \%$ CI 0.58 to 0.94$)$. A GRADE analysis indicated that the overall quality of the evidence supporting this outcome was low due to high risk of bias (one study was single-blind) and sparse data (93 events). One study (87 patients) found a reduction in endoscopic relapse rates favouring 6-mercaptopurine over placebo. Seventeen per cent of 6-mercaptopurine patients had an endoscopic relapse at two years compared to $42 \%$ of placebo patients (RR $0.40,95 \%$ CI 0.19 to 0.83 ). A GRADE analysis indicated that the overall quality of the evidence for this outcome was low due to very sparse data ( 25 events). A pooled analysis of five studies ( $\mathrm{n}=425$ patients) showed no difference in clinical relapse rates at one or two years between purine analogues and 5-ASA agents. Sixty-three per cent of patients in the purine analogues group experienced a clinical relapse compared to 54\% of 5-ASA patients (RR 1.15 , 95\% CI 0.99 to 1.34 ). A GRADE analysis indicated that the overall quality of the evidence supporting this outcome was very low due to high risk of bias (two open-label studies), sparse data (249 events) and moderate heterogeneity $\left(\mathrm{I}^{2}=45 \%\right)$. There was no difference in endoscopic relapse at 12 months between azathioprine and 5-ASA (RR 0.78, 95\% CI 0.52 to $1.17 ; 1$ study, 35 patients). A GRADE analysis indicated that the overall quality of the evidence for this outcome was very low due to high risk of bias (open-label study) and very sparse data (26 events). There was a reduction in endoscopic relapse at 24 months favouring 6-mercaptopurine over 5-ASA patients. Seventeen per cent of 6-mercaptopurine patients had an endoscopic relapse compared to $48 \%$ of 5-ASA patients (RR $0.36,95 \%$ CI 0.18 to 0.72; 1 study, 91 patients). A GRADE analysis indicated that the overall quality of the evidence for this outcome was low due to very sparse data (29 events). Adverse events that required withdrawal were more common in the purine analogue group compared to 5-ASA. Twenty per cent of patients in the purine analogue group withdrew due to adverse events compared to $10 \%$ of 5-ASA patients (RR 2.07, $95 \%$ CI 1.26 to 3.39; 5 studies, 423 patients). The results for withdrawal due to adverse events between purine analogues and placebo or for other comparisons were uncertain. Commonly reported adverse events across all studies included leucopenia, arthralgia, abdominal pain or severe epigastric intolerance, elevated liver enzymes, nausea and vomiting, pancreatitis, anaemia, exacerbation of Crohn's disease, nasopharyngitis, and flatulence.

\section{Authors' conclusions}

Purine analogues may be superior to placebo for maintenance of surgically-induced remission in patients with CD, although this is based on two small studies. The results for efficacy outcomes between purine analogues and 5-ASA agents were uncertain. However, patients taking purine analogues were more likely than 5-ASA patients to discontinue therapy due to adverse events. No firm conclusions can be drawn from the two small studies that compared azathioprine to infliximab or adalimumab. Adalimumab may be superior to azathioprine but further research is needed to confirm these results. Further research investigating the efficacy and safety of azathioprine and 6-mercaptopurine in comparison to other active medications in patients with surgically-induced remission of CD is warranted.

\section{PLAIN LANGUAGE SUMMAY}

\section{Azathioprine and 6-mercaptopurine for the maintenance of surgically-induced remission in Crohn's disease}

Prevention of clinical relapse (resumption of symptoms of active disease) and endoscopic relapse (signs of mucosal inflammation upon examination with an endoscope) are key objectives in the management of Crohn's disease. There is no treatment currently available that completely prevents relapse and is without significant side-effects. The purpose of this systematic review was to examine the effectiveness and side effects of purine analogue medications (azathioprine and 6-mercaptopurine) used to prevent relapse in Crohn's patients in surgically-induced remission

This review identified seven studies that included a total of 584 participants. One study compared azathioprine to placebo (e.g. a sugar pill). Another study compared 6-mercaptopurine to 5-aminosalicylic acid (5-ASA) or placebo. Three studies compared azathioprine to 5-ASA drugs. One small study compared azathioprine to both 5-ASA and adalimumab (a biological drug that is a tumour necrosis 
factor-alpha antagonist). One small study compared azathioprine to infliximab (a biological drug that is a tumour necrosis factor-alpha antagonist). The study that compared azathioprine to infliximab (22 patients) found that the effects on the proportion of patients who had a clinical or endoscopic relapse were uncertain. A small study (33 patients) found reduced clinical and endoscopic relapse rates favouring adalimumab over azathioprine. No firm conclusions can be drawn from the two small studies that compared azathioprine to infliximab or adalimumab. Adalimumab may be superior to azathioprine but further research is needed to confirm these results. A pooled analysis of two studies (168 patients) suggests that purine analogues may be superior to placebo for preventing clinical relapse in Crohn's patients in surgically-induced remission. One study (87 patients) found a reduction in endoscopic relapse rates favouring 6-mercaptopurine over placebo. A pooled analysis of five studies (425 patients) found no difference in clinical relapse rates between purine analogues and 5-ASA agents. One study (35 patients) found no difference in endoscopic relapse at 12 months between azathioprine and 5-ASA. Another study (91 patients) found reduced endoscopic relapse rates at 24 months favouring 6-mercaptopurine over 5-ASA patients. Patients taking purine analogues were more likely than 5-ASA patients to discontinue therapy due to side effects. Commonly reported side effects across the studies included leucopenia (a decrease in the number of white blood cells), arthralgia (joint pain), abdominal pain or severe epigastric intolerance, elevated liver enzymes, nausea and vomiting, pancreatitis (inflammation of the pancreas), anaemia (a decrease in the number of red blood cells), exacerbation (worsening) of Crohn's disease, nasopharyngitis (common cold), and flatulence. The results of this review need to be interpreted with caution as they are based on small numbers of patients and the overall quality of the evidence from the studies was rated as low or very low due to lack of precision of the results, inconsistent results across studies and the low methodological quality of some studies. Further research investigating the effectiveness and side effects of azathioprine and 6-mercaptopurine in comparison to other medications in patients with surgically-induced remission of Crohn's disease is warranted. 


\section{SUMMARY OF FINDINGSFOR THE MAIN COMPARISON [Explanation]}

\section{Azathioprine (AZA) or 6-mercaptopurine (6-MP) versus placebo for maintenance of surgically-induced remission in Crohn's disease}

Patient or population: Patients in remission after surgery for Crohn's disease

Settings: Outpatient

Intervention: AZA or 6-MP versus placebo

\begin{tabular}{|c|c|c|c|c|c|c|}
\hline \multirow[t]{3}{*}{ Outcomes } & \multicolumn{2}{|c|}{ Illustrative comparative risks* (95\% CI) } & \multirow{3}{*}{$\begin{array}{l}\text { Relative effect } \\
(95 \% \text { CI })\end{array}$} & \multirow{3}{*}{$\begin{array}{l}\text { No of Participants } \\
\text { (studies) }\end{array}$} & \multirow{3}{*}{$\begin{array}{l}\text { Quality of the evidence } \\
\text { (GRADE) }\end{array}$} & \multirow[t]{3}{*}{ Comments } \\
\hline & Assumed risk & Corresponding risk & & & & \\
\hline & Control & $\begin{array}{l}\text { AZA or 6-MP versus } \\
\text { placebo }\end{array}$ & & & & \\
\hline Clinical relapse & 630 per $1000^{1}$ & $\begin{array}{l}\mathbf{4 6 6} \text { per } \mathbf{1 0 0 0} \\
(365 \text { to } 592)\end{array}$ & $\begin{array}{l}\text { RR } 0.74 \\
(0.58 \text { to } 0.94)\end{array}$ & $\begin{array}{l}168 \\
\text { (2 studies) }\end{array}$ & $\begin{array}{l}\oplus \oplus \bigcirc \bigcirc \\
\mathbf{l o w}^{2,3}\end{array}$ & \\
\hline $\begin{array}{l}\text { Endoscopic relapse (6- } \\
\text { MP study) }\end{array}$ & 425 per $1000^{1}$ & $\begin{array}{l}170 \text { per } 1000 \\
(81 \text { to } 353)\end{array}$ & $\begin{array}{l}\text { RR } \mathbf{0 . 4 0} \\
(0.19 \text { to } 0.83)\end{array}$ & $\begin{array}{l}87 \\
\text { (1 study) }\end{array}$ & $\begin{array}{l}\oplus \oplus \bigcirc \bigcirc \\
\text { low }^{4}\end{array}$ & \\
\hline
\end{tabular}

*The basis for the assumed risk (e.g. the median control group risk across studies) is provided in footnotes. The corresponding risk (and its $95 \%$ confidence interval) is based on the assumed risk in the comparison group and the relative effect of the intervention (and its $95 \% \mathrm{Cl}$ ).

Cl: Confidence interval; RR: Risk ratio

GRADE Working Group grades of evidence

High quality: Further research is very unlikely to change our confidence in the estimate of effect.

Moderate quality: Further research is likely to have an important impact on our confidence in the estimate of effect and may change the estimate.

Low quality: Further research is very likely to have an important impact on our confidence in the estimate of effect and is likely to change the estimate.

Very low quality: We are very uncertain about the estimate.

${ }^{1}$ Control group risk estimates come from control arm of meta-analysis, based on included trials.

2 Sparse data (93 events).

${ }^{3}$ High risk of bias in one study in pooled analysis due to single-blind design.

${ }^{4}$ Very sparse data (25 events). 


\section{B A C K G R O U N D}

\section{Description of the condition}

Crohn's disease (CD) is a chronic inflammatory disorder that can involve any part of the gastrointestinal tract. There is no cure for the disease, and management strategies are mainly focused on induction and maintenance of remission. Approximately $75 \%$ of patients with $\mathrm{CD}$ will eventually undergo surgical resection ( Bernell 2000), and this can induce remission. However endoscopic recurrence of disease has been reported to be as high as $73 \%$ at one year post surgery (Rutgeerts 1990), and clinical relapse rates have been reported to range from 22 to $55 \%$ at five years post surgery (Williams 1990). There is no standard therapy for the prevention of postoperative recurrence in CD (Hanauer 2001). A number of agents have been studied, but considerable uncertainty remains as to the efficacy of such treatments.

\section{Description of the intervention}

Corticosteroids, the mainstay of treatment of acute exacerbations, are not effective for maintenance of remission in CD (Steinhart 2003), and chronic use is limited by numerous adverse events. 5Aminosalicylic acid agents have been shown to be safe and may be effective for maintenance of post-surgical remission, although the existing data suggests that the efficacy of these agents may be limited (Gordon 2011). Probiotics and budesonide do not appear to provide any benefit for maintenance of surgically-induced remission (Rolfe 2006; Benchimol 2009; Doherty 2009). Nitroimidazole antibiotics may reduce the risk of relapse in surgically-induced remission (Doherty 2009). However these agents are not well tolerated and are associated with a higher risk of serious adverse events (Doherty 2009). TNF-alpha antagonists may provide a benefit in post-operative Crohn's disease but these agents are expensive. One small study suggests that infliximab may provide a benefit for reducing the risk of relapse in surgically-induced remission (Regueiro 2009). Another small study suggests that adalimumab my be superior to azathioprine for reducing the risk of relapse in post-operative CD patients (Savarino 2013). Further research is needed to confirm these benefits, Purine analogues such as azathioprine and 6-mercaptopurine have been extensively used for maintenance of remission in both Crohn's disease and ulcerative colitis and are relatively inexpensive.

\section{How the intervention might work}

Azathioprine is a prodrug which is non-enzymatically degraded to 6 -mercaptopurine which in turn is metabolised to the active component, 6-thioguanine nucleotide (6-TGN). 6-TGN is thought to work by inhibiting the proliferation of $\mathrm{T}$ and $\mathrm{B}$ lymphocytes and reducing the numbers of cytotoxic $\mathrm{T}$ cells and plasma cells.
There are some trial data which suggest that neutrophil count is a predictor of induction and maintenance of remission (Colonna 1994), which may suggest the mechanism of action, although this is not well understood. The major limiting factor for long term use has been the occurrence of adverse events in approximately $10 \%$ of patients leading to withdrawal of therapy (Hafraoui 2002), with dose-dependent and idiosyncratic adverse events occurring.

\section{Why it is important to do this review}

Relatively few studies have been published that investigate the role of azathioprine or 6-mercaptopurine for maintenance of remission following surgery in patients with $\mathrm{CD}$. One multicentre randomised placebo controlled trial involving 81 patients found a significant reduction in endoscopic recurrence when azathioprine was used in conjunction with metronidazole in comparison to metronidazole alone (D'Haens 2008). In another multicentre randomised controlled trial, it was concluded that 6-mercaptopurine was more effective than either mesalamine or placebo at preventing postoperative recurrence at 24 months following surgery (Hanauer 2001). However, a single-center randomised open-label trial found no significant difference in clinical relapse rates between azathioprine and mesalamine (Ardizzone 2004). An up-todate systematic review using the Cochrane Collaboration format is indicated to summarise the current evidence on the use of purine analogues for the maintenance of surgically induced remission in CD.

\section{O B J E C T I VES}

The primary objective was to evaluate the efficacy and safety of azathioprine and 6-mercaptopurine for maintenance of surgicallyinduced remission in CD.

\section{METHODS}

\section{Criteria for considering studies for this review}

\section{Types of studies}

Randomised controlled trials were considered for inclusion.

\section{Types of participants}

Patients of any age with CD who were in remission following surgery, defined by a recognized CD activity index or endoscopy, or who had undergone a curative surgical resection, as defined by the authors of the primary studies were considered for inclusion. 


\section{Types of interventions}

Trials which compared azathioprine or 6-mercaptopurine to placebo or another active intervention with treatment durations of at least six months were considered for inclusion.

\section{Types of outcome measures}

\section{Primary outcomes}

The primary outcome measure was clinical relapse or endoscopic relapse as defined by the primary studies.

\section{Secondary outcomes}

Secondary outcomes included the incidence of adverse events, withdrawal due to adverse events, and serious adverse events. Adverse events that are known to be associated with azathioprine or 6-mercaptopurine were reported. These adverse events could include:

a. Bone marrow suppression: pancytopenia, leucopenia, neutropenia, thrombocytopenia;

b. Hypersensitive reactions: malaise, vomiting, diarrhoea, rash, hypotension;

c. Malignancy

d. Liver function impairment, jaundice;

e. Pancreatitis;

f. Pulmonary: pneumonitis; and

g. Renal: interstitial nephritis.

\section{Search methods for identification of studies}

\section{Electronic searches}

A. Electronic searching

The following electronic databases were searched for relevant studies:

1. PubMed (from inception to April 30, 2014);

2. MEDLINE (from inception to April 30, 2014);

3. EMBASE (from inception to April 30, 2014);

4. Cochrane Central Register of Controlled Trials (CENTRAL, on 30 April 2014); and

5. Cochrane Inflammatory Bowel Disease and Functional Bowel Disortders Group Specialized Trials Register.

The search strategy was not limited by language. The search strategy used for each database is reported in Appendix 1. There is some evidence that data from abstracts can be inconsistent with data in published articles (Pitkin 1999). Thus studies that were reported in abstract form only were not included in this review.

\section{Searching other resources}

B. Reference searching

The references of all identified studies were inspected for more trials.

C. Personal contacts

Leaders in the field were contacted to try to identify other studies. D. Drug companies

The manufacturers of azathioprine and 6-mercaptopurine were contacted for any additional data.

\section{Data collection and analysis}

All identified abstracts and results from searches were reviewed by two authors (MG and KV). If the reference appeared relevant, a full copy of the study was obtained.

\section{Selection of studies}

Two authors (MG and KV), after reading the full texts, independently assessed the eligibility of all trials identified based on the inclusion criteria above. Disagreement among authors was discussed and agreement reached by consensus.

\section{Data extraction and management}

A data extraction form was developed to extract information on relevant features and results of included studies. Two authors (MG and $\mathrm{KV}$ ) independently extracted and recorded data on the predefined checklist. Extracted data included the following items:

a. characteristics of patients: age, sex, disease distribution, disease duration, disease activity index;

b. total number of patients originally assigned to each treatment group;

c. intervention: dose of azathioprine or 6-mercaptopurine;

d. control: placebo, other drugs;

e. concurrent medications; and

f. outcomes: time of assessment, length of follow up, type of Crohn's disease activity index used, definitions of remission and relapse, relapse rates, adverse events.

\section{Assessment of risk of bias in included studies}

The methodological quality of selected trials was assessed independently by two authors (MG and KV) using the Cochrane risk of bias tool (Higgins 2011).

Factors assessed included:

1. sequence generation (i.e. was the allocation sequence adequately generated?);

2. allocation sequence concealment (i.e. was allocation adequately concealed?);

3. blinding (i.e. was knowledge of the allocated intervention adequately prevented during the study?); 
4. incomplete outcome data (i.e. were incomplete outcome data adequately addressed?);

5. selective outcome reporting (i.e. are reports of the study free of suggestion of selective outcome reporting?);

6. other potential sources of bias (i.e. was the study apparently free of other problems that could put it at a high risk of bias?).

A judgement of 'Yes' indicates low risk of bias, 'No' indicates high risk of bias, and 'Unclear' indicates unclear or unknown risk of bias. Disagreements were resolved by consensus. Study authors were contacted for further information when insufficient information was provided to determine the risk of bias.

The overall quality of evidence was assessed using the GRADE approach (Guyatt 2008; Schünemann 2011). The GRADE approach appraises the quality of a body of evidence based on the extent to which one can be confident that an estimate of effect or association reflects the item being assessed. Randomised trials start as high quality evidence, but may be downgraded due to: risk of bias (methodological quality), indirectness of evidence, unexplained heterogeneity, imprecision (sparse data) and publication bias. The overall quality of the evidence for each outcome was determined after considering each of these factors and graded as:

- High: further research is very unlikely to change confidence in the estimate of effect;

- Moderate: further research is likely to have an important impact on confidence in the estimate of effect and may change the estimate;

- Low: further research is very likely to have an important impact on confidence in the estimate of effect and is likely to change the estimate; and

- Very low: any estimate of effect is very uncertain.

\section{Measures of treatment effect}

The Cochrane Collaboration review manager (RevMan) software (version 5.3) was used for data analysis (RevMan 2014). We calculated the risk ratio and corresponding $95 \%$ confidence interval (95\% CI) for dichotomous outcomes. We planned to calculate the mean difference (MD) and corresponding $95 \%$ CI for continuous outcomes measured using the same units. We planned to calculate the standardized mean difference (SMD) and corresponding 95\% $\mathrm{CI}$ for continuous outcomes where different scales were used to evaluate the same outcome.

\section{Unit of analysis issues}

When cross-over trials were included, data from the first phase of the study were extracted for analysis (i.e. before the crossover occurred). Separate analyses were conducted for comparisons between azathioprine or 6-mercaptopurine versus placebo, and azathioprine or 6-mercaptopurine versus active comparator (e.g. mesalamine). If studies randomised subjects to more than one azathioprine or 6-mercaptopurine treatment arm, these were combined for the primary analysis. Although some studies reported more than one efficacy or safety event per subject, the primary analysis considered only the proportion of subjects who experienced at least one event.

\section{Dealing with missing data}

Data were analysed according to the intention-to-treat principle. Patients with final missing outcomes were assumed to have relapsed.

\section{Assessment of heterogeneity}

Heterogeneity among trial results was assessed by visual inspection of forest plots and by calculating the $\mathrm{Chi}^{2}$ test (a P value of 0.10 was regarded as statistically significant heterogeneity). We also used the $\mathrm{I}^{2}$ statistic to quantity the effect of heterogeneity (Higgins 2003). A random-effects model was used in situations of unexplained heterogeneity. We conducted sensitivity analyses as appropriate to investigate heterogeneity. For example, if a pooled analysis showed statistically significant heterogeneity and a visual inspection of the forest plot identified studies that may have contributed to this heterogeneity the analysis was repeated excluding these studies to see if this explained the heterogeneity.

\section{Assessment of reporting biases}

We planned to investigate the possibility of a publication bias through the construction of funnel plots (trial effects versus trial size), although this was not completed as the number of studies was small.

\section{Data synthesis}

Data from individual trials were combined for meta-analysis if the interventions, patient groups and outcomes were sufficiently similar (determined by consensus). We calculated the pooled RR and corresponding 95\% CI for dichotomous outcomes. Meta-analysis was carried out using a fixed-effect model. A random-effects model was used in situations of statistically significant heterogeneity. Data were not to be pooled for meta-analysis if a high degree of heterogeneity was detected (i.e. $\mathrm{I}^{2}>75 \%$ ).

\section{Subgroup analysis and investigation of heterogeneity}

Subgroup analyses were planned to further study the effects of a number of variables on the outcomes, when appropriate data were available. However there were not sufficient studies to carry out such analyses. Planned subgroup analyses included:

a. Length of follow up; and

b. Drug type (i.e. azathioprine or 6-mercaptopurine). 


\section{Sensitivity analysis}

Sensitivity analyses based on random-effects versus fixed-effect models were planned where appropriate data or numbers of studies were available. Sensitivity analysis was also undertaken to explore possible explanations for significant heterogeneity.

\section{RE S U L T S}

\section{Description of studies}

See Characteristics of included studies and Characteristics of excluded studies.

The electronic database search on 30 April 2014 identified 745 studies. After removal of duplicates, 635 studies were screened for inclusion. Of these, 24 studies were judged to be potentially relevant and subjected to full text review (See Figure 1). Experts were contacted, but no responses were received and no further studies were identified from drug companies. 
Figure I. Study flow diagram.

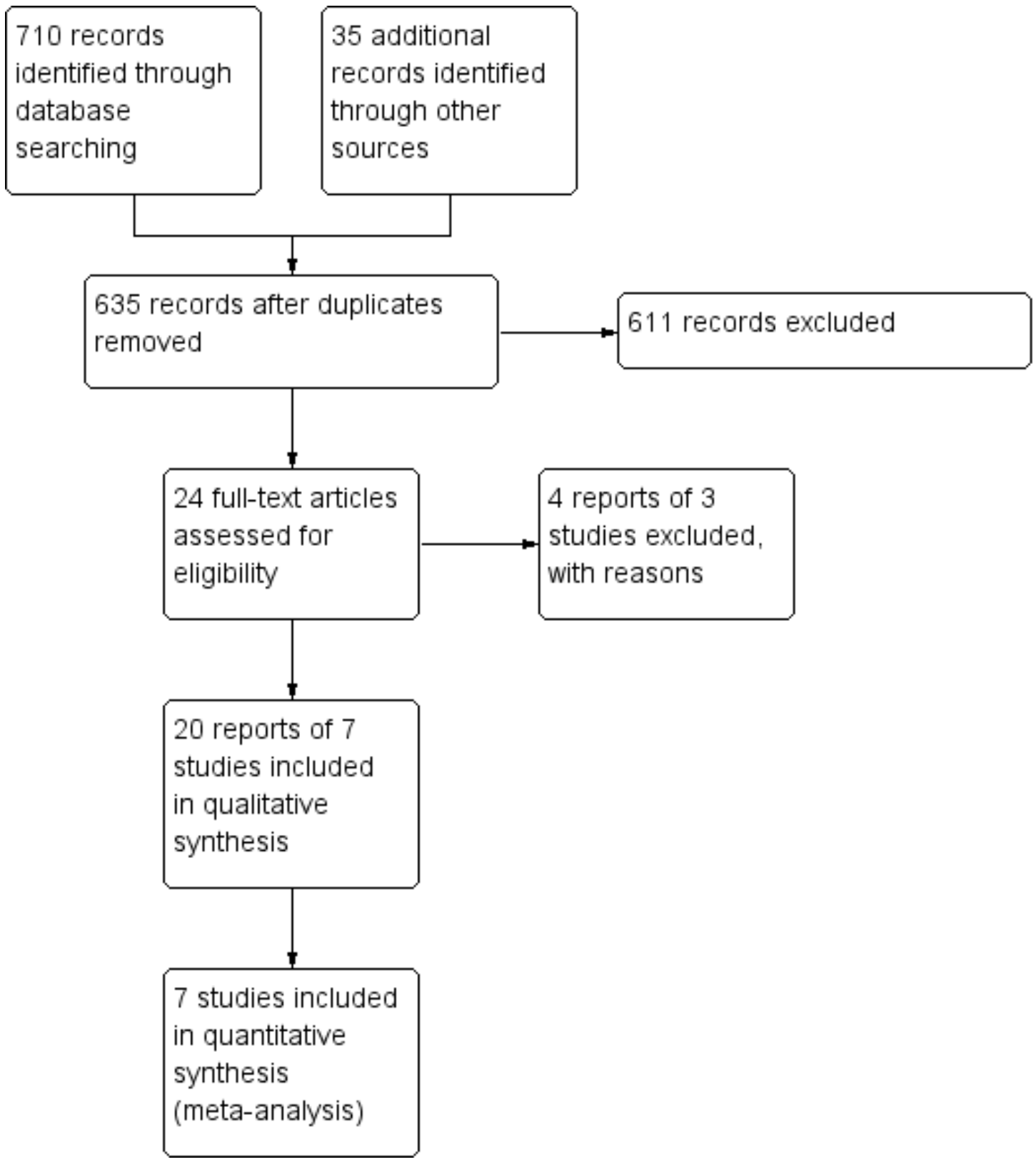


Four reports of three studies were excluded for failing to meet the inclusion criteria. One study was excluded because it was not a randomised controlled trial as confirmed by the author (Nos 2000). The other two studies were excluded because all patients received azathioprine as part of their post-surgical maintenance therapy (Mañosa 2013; Ferrante 2014).

Twenty reports of seven studies satisfied the inclusion criteria and were included in the review. Three studies compared azathioprine to 5-aminosalicylic acid (Ardizzone 2004; Herfarth 2006; Reinisch 2010). D'Haens 2008 compared azathioprine to placebo. All patients in this study were taking concurrent metronidazole or ornidazole. Hanauer 2004 compared 6-mercaptopurine to both 5-aminosalicylic acid and placebo. Savarino 2013 compared azathioprine to both 5-aminosalicylic acid and adalimumab. Armuzzi
2013 was a randomised open-label pilot study that compared azathioprine to infliximab. All patients in this study took oral metronidazole for two weeks post-surgery. There were no cross-over trials. The total number of participants in the seven studies was 584. All participants were adult patients with Crohn's disease, the majority of whom were recruited within two weeks of surgery or before hospital discharge after remission-inducing surgery. The 78 participants in one study were enrolled between 6 and 24 months postoperatively and were in clinical remission but had endoscopic recurrence as an inclusion criterion (Reinisch 2010).

\section{Risk of bias in included studies}

A summary of the risk of bias analysis is shown in Figure 2. 
Figure 2. Risk of bias summary: review authors' judgements about each risk of bias item for each included study.

\begin{tabular}{|c|c|c|c|c|c|c|}
\hline & 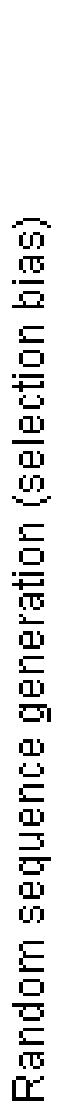 & 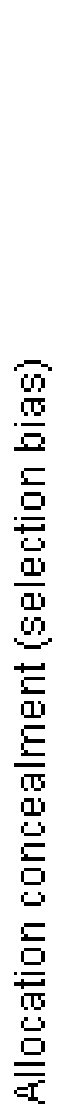 & 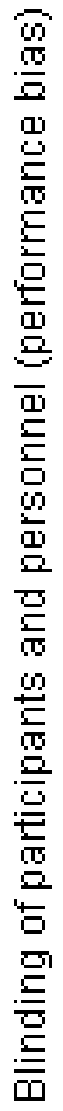 & 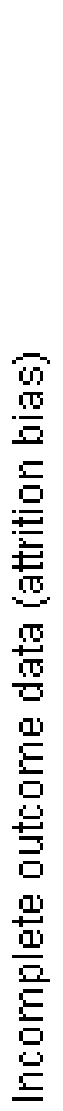 & 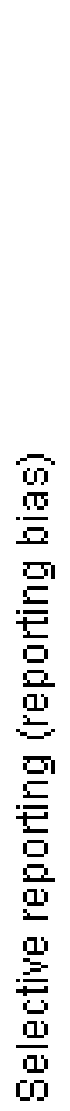 & 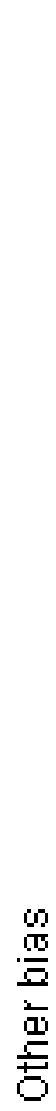 \\
\hline Ardizone 2004 & + & $?$ & & $?$ & $?$ & \\
\hline Armuzi 2013 & $?$ & $?$ & & & & \\
\hline D'Haens 2008 & & & & & & \\
\hline Hanauer 2004 & & & & & & \\
\hline Herfarth 2006 & & + & & & & \\
\hline Reinisch 2010 & 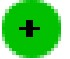 & $?$ & & & & \\
\hline Savarino 2013 & & & & & & \\
\hline
\end{tabular}


Six studies were rated as low risk for random sequence generation (selection bias) because these studies employed computer-generated randomisation (Ardizzone 2004; Hanauer 2004; Herfarth 2006; D’Haens 2008; Reinisch 2010; Savarino 2013). Armuzzi 2013 was rated as unclear risk of bias for random sequence generation because the method of randomisation was not described in the manuscript. Four studies were rated as low risk of bias for allocation concealment (selection bias) (Hanauer 2004; Herfarth 2006; D'Haens 2008; Savarino 2013). Three studies were rated as unclear risk of bias for allocation concealment as the methods were not clearly described in the manuscripts (Ardizzone 2004; Reinisch 2010; Armuzzi 2013). The authors were contacted, but no further information was given.

Three studies were double-blinded and were judged to be at low risk of bias for blinding of participants and personnel (performance bias) (Hanauer 2004; Herfarth 2006; Reinisch 2010). The D'Haens 2008 study was investigator-blinded and was judged to be at high risk of bias for blinding of participants. Three studies were open-label and were judged to be at high risk of bias for blinding of participants and personnel (Ardizzone 2004; Armuzzi 2013; Savarino 2013).

Six studies reported full and appropriate data and satisfactorily documented withdrawals and dropouts and were therefore judged to be at low risk of bias for incomplete outcome data (attrition bias) and selective reporting (reporting bias) (Hanauer 2004; Herfarth 2006; D'Haens 2008; Reinisch 2010; Armuzzi 2013; Savarino 2013). Ardizzone 2004 was judged to be at unclear risk of bias for incomplete outcome data and selective reporting owing to inadequately described outcomes and potentially selective data reporting.

All seven studies were judged to be a low risk of bias for other sources of bias. Reinisch 2010 was funded by a drug company with some of the authors employed by the drug company although the extent of their involvement was unclear.

\section{Effects of interventions}

See: Summary of findings for the main comparison Azathioprine or 6-mercaptopurine versus placebo for maintenance of surgically-induced remission in Crohn's disease; Summary of findings 2 Azathioprine or 6-mercaptopurine versus 5aminosalicylic acid for maintenance of surgically-induced remission in Crohn's disease; Summary of findings 3 Azathioprine versus infliximab for maintenance of surgicallyinduced remission in Crohn's disease; Summary of findings 4 Azathioprine versus adalimumab for maintenance of surgicallyinduced remission in Crohn's disease

\section{Azathioprine or 6-mercaptopurine versus placebo}

Two studies with a total of 168 participants compared azathioprine or 6-mercaptopurine to placebo (Hanauer 2004; D'Haens 2008). In one of these studies all patients were also taking either metronidazole or ornidazole (D’Haens 2008).

\section{Efficacy}

Meta-analysis of two studies with 168 participants comparing azathioprine or 6-mercaptopurine to placebo, showed a statistically significant difference in clinical relapse rates favouring purine analogues. Forty-eight per cent of patients in the purine analogue group experienced a clinical relapse compared to $63 \%$ of placebo patients (RR 0.74, 95\% CI 0.58 to 0.94; See Figure 3). No heterogeneity was detected for this comparison $\left(\mathrm{P}=0.53, \mathrm{I}^{2}=0 \%\right)$. However, there was clinical and methodological heterogeneity between these two studies, regarding the choice of purine analogue and the use of other medications. A GRADE analysis indicated that the overall quality of the evidence for this outcome was low due to high risk of bias (one study in the pooled analysis was single blind) and sparse data (93 events, See Summary of findings for the main comparison). A sensitivity analysis using a random-effects model showed a statistically significant difference in clinical relapse rates favouring purine analogues (RR 0.76, 95\% CI 0.61 to 0.95 ).

Figure 3. Forest plot of comparison: 2 AZA or 6MP versus placebo, outcome: 2.1 Clinical relapse (fixedeffect).

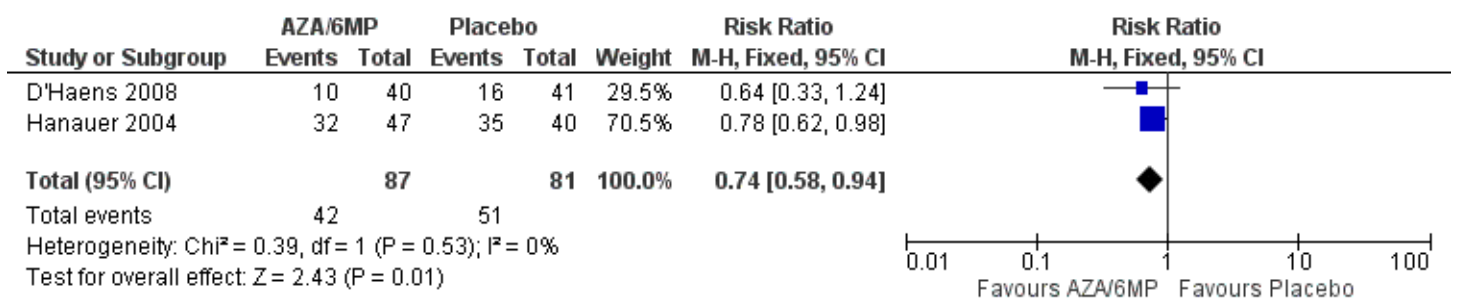

Azathioprine and 6-mercaptopurine for maintenance of surgically-induced remission in Crohn's disease (Review) 
One study reported on endoscopic relapse at two years as an outcome (Hanauer 2004). There was a statistically significant difference in endoscopic relapse rates favouring 6-mercaptopurine. Seventeen per cent of patients in the 6-mercaptopurine group had an endoscopic relapse at two years compared to $42 \%$ of placebo patients (RR $0.40,95 \%$ CI 0.19 to 0.83 ). A GRADE analysis indicated that the overall quality of the evidence for this outcome was low due to very sparse data ( 25 events, See Summary of findings for the main comparison).

\section{Safety}

Both studies reported on the proportion of patients who withdrew due to an adverse event. Adverse events leading to withdrawal were not significantly more common in the azathioprine or 6-mercaptupurine groups. Fifteen per cent of patients in the purine analogue group withdrew due to adverse events compared to $11 \%$ of placebo patients (RR 1.33, 95\% CI 0.59 to 2.98). No heterogeneity was detected for this comparison $\left(\mathrm{P}=0.32, \mathrm{I}^{2}=1 \%\right)$.

Common adverse events reported in the study that compared azathioprine to placebo included metallic taste, headache, paraesthesias, epigastric pain, nausea, arthralgia, angina, skin rash, and elevated liver enzymes (D'Haens 2008). Common adverse events reported in the study that compared 6-mercaptopurine to placebo included leukopenia, alopecia, diarrhoea, flatus, gastrointestinal bleeding, phlebitis, abdominal pain, and headache (Hanauer 2004).

\section{Azathioprine or 6-mercaptopurine versus 5-aminosalicylic acid}

Five studies involving 425 participants compared either azathioprine or 6-mercaptopurine to 5-aminosalicylic acid (Ardizzone
2004; Hanauer 2004; Herfarth 2006; Reinisch 2010; Savarino 2013). Reinisch 2010 enrolled patients who were in clinical remission but had endoscopic recurrence as an inclusion criteria.

\section{Efficacy}

Five studies involving 425 patients reported on clinical relapse at one or two years as an outcome (Ardizzone 2004; Hanauer 2004; Herfarth 2006; Reinisch 2010; Savarino 2013). The pooled analysis showed no statistically significant difference in clinical relapse rates between purine analogues and 5-aminosalicylates. Sixty-three per cent (137/218) of patients in the purine analogues group experienced a clinical relapse compared to $54 \%(112 / 207)$ of patients in the 5-aminosalicylates group (RR 1.15, 95\% CI 0.99 to 1.34; See Figure 4). Statistical heterogeneity was moderate (I $2=45 \%)$. A GRADE analysis indicated that the overall quality of the evidence for the primary outcome (clinical relapse) was very low due to high risk of bias (two studies in the pooled analysis were not blinded), moderate heterogeneity and sparse data (249 events, see Summary of findings 2). A sensitivity analysis using a random-effects model showed no statistically significant difference in clinical relapse rates between the two groups (RR 1.14, 95\% CI 0.93 to 1.41 ; see Analysis 2.2). A sensitivity analysis excluding the study that included patients with endoscopic recurrence (Reinisch 2010), showed no statistically significant difference in rates of clinical relapse (RR 1.06, 95\% CI 0.91 to 1.24; see Analysis 2.3). However, there was far less statistical heterogeneity for this comparison ( $\mathrm{P}=0.36, \mathrm{I}^{2}=6 \%$ ) which suggests that the heterogeneity can be explained by the inclusion of the study that enrolled patients with endoscopic recurrence. A GRADE analysis indicated that the overall quality of the evidence for this outcome was low due to high risk of bias (two studies in the pooled analysis were not blinded) and sparse data (214 events, See Summary of findings 2).

Figure 4. Forest plot of comparison: I AZA/6MP vs 5-ASA, outcome: I.I Clinical relapse (fixed-effect).

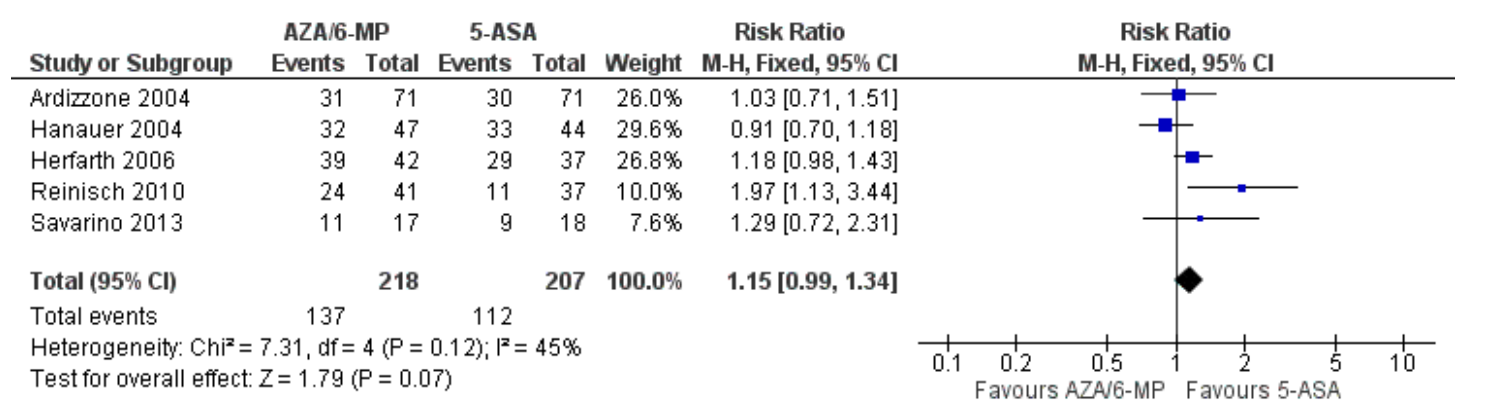

Azathioprine and 6-mercaptopurine for maintenance of surgically-induced remission in Crohn's disease (Review) 
A subgroup analysis by drug type suggests a statistically significant benefit for 5-aminosalicylates over azathioprine but no statistically significant difference for 5-aminosalicylates over 6-mercaptopurine. Sixty-eight per cent of 6-mercaptopurine patients had a clinical relapse compared to $75 \%$ of 5 -aminosalicylate patients (RR $0.91,95 \%$ CI 0.70 to 1.18 ; 91 patients 1 study). Sixtyone per cent of azathioprine patients experienced a clinical relapse compared to $48 \%$ of 5-aminosalicylate patients (RR 1.25, 95\% CI 1.04 to 1.51 ; 4 studies, 334 patients). There was no significant statistical heterogeneity $\left(\mathrm{P}=0.28, \mathrm{I}^{2}=22 \%\right)$ for this comparison. A GRADE analysis indicated that the overall quality of the evidence for this outcome was low due to high risk of bias (two studies in the pooled analysis were not blinded) and sparse data (184 events, See Summary of findings 2). A sensitivity analysis excluding the study that included patients with endoscopic recurrence (Reinisch 2010), showed no statistically significant difference in clinical relapse rates (RR $1.13,95 \%$ CI 0.93 to $1.38 ; 3$ studies, 256 patients).

A subgroup analysis by length of follow-up suggests a statistically significant benefit for 5-aminosalicylates over antimetabolites at 12 months but not at 24 months. Seventy-six per cent of patients in the antimetabolite group experienced a clinical relapse at 12 months compared to $54 \%$ of 5 -aminosalicylate patients (RR 1.40 , 95\% CI 1.12 to $1.74 ; 2$ studies, 157 patients). A high degree of heterogeneity was detected for this comparison ( $\left.\mathrm{P}=0.04, \mathrm{I}^{2}=77 \%\right)$. At 24 months, $55 \%$ of patients in the antimetabolite group experienced a clinical relapse compared to $54 \%$ of 5-aminosalicylate patients (RR 1.01, 95\% CI 0.81 to 1.24; 3 studies, 268 patients). No heterogeneity was detected for this comparison ( $\mathrm{P}=0.51$, I $2=0 \%$ ). A sensitivity analysis excluding the study that included patients with endoscopic recurrence (Reinisch 2010), showed no statistically significant difference in rates of clinical relapse at one year (RR $1.18,95 \%$ CI 0.98 to 1.43 ).

Two studies reported on endoscopic relapse at one or two years as an outcome (Hanauer 2004; Savarino 2013). These studies were not pooled for analysis due to a high degree of heterogeneity. There was no statistically significant difference in endoscopic relapse at 12 months between azathioprine and 5-aminosalicylate patients. Sixty-five per cent of azathioprine patients had an endoscopic relapse compared to $83 \%$ of 5-aminosalicylate patients (RR $0.78,95 \%$ CI 0.52 to 1.17 ). A GRADE analysis indicated that the overall quality of the evidence for this outcome was very low due to high risk of bias (the study was not blinded) and very sparse data (26 events, See Summary of findings 2). There was a statistically significant difference in the rate of endoscopic relapse at 24 months between 6-mercaptopurine and 5-aminosalicylate patients. Seventeen per cent of 6-mercaptopurine patients had an endoscopic relapse compared to $48 \%$ of 5 -aminosalicylate patients (RR $0.36,95 \%$ CI 0.18 to 0.72 ). A GRADE analysis indicated that the overall quality of the evidence for this outcome was low due to very sparse data (29 events, See Summary of findings 2).

\section{Safety}

Four studies involving 334 patients reported on the proportion of patients who had at least one adverse event (Ardizzone 2004; Herfarth 2006; Reinisch 2010; Savarino 2013). The pooled analysis showed no statistically significant difference in the proportion of patients who experienced an adverse event. Sixty-two per cent $(106 / 171)$ of patients in the azathioprine group experienced an adverse event compared to $56 \%(92 / 163)$ of patients in the 5aminosalicylates group (RR $1.08,95 \%$ CI 0.93 to 1.27 ). No significant heterogeneity was found for this comparison $(\mathrm{P}=0.20$, I $2=36 \%)$.

Five studies involving 423 patients reported on the proportion of patients who withdrew due to an adverse event (Ardizzone 2004; Hanauer 2004; Herfarth 2006; Reinisch 2010; Savarino 2013). Adverse events that required withdrawal were significantly more common in the purine analogue group compared to the 5-aminosalicylic acid group. Twenty per cent of patients in the purine analogue group withdrew due to an adverse event compared to $10 \%$ of 5-aminosalicylate patients (RR 2.07, 95\% CI 1.26 to 3.39). No heterogeneity was detected for this comparison $\left(\mathrm{P}=0.53, \mathrm{I}^{2}\right.$ $=0 \%$ ). A subgroup analysis by drug type suggests a significantly higher risk of withdrawal due to adverse events for patients receiving azathioprine but not for 6-mercaptopurine. Twenty per cent of patients in the azathioprine group withdrew due to an adverse event compared to $9 \%$ of 5-aminosalicylate patients (RR 2.35, 95\% CI 1.31 to 4.22 ; 4 studies, 332 patients). No heterogeneity was detected for this comparison $\left(\mathrm{P}=0.47, \mathrm{I}^{2}=0 \%\right)$.

Nineteen per cent of 6-mercaptopurine patients withdrew due to an adverse event compared to $14 \%$ of 5 -aminosalicylate patients (RR $1.40,95 \% 0.54$ to 3.62). Two studies involving 169 patients reported on the proportion of patients who had a serious adverse event (Hanauer 2004; Reinisch 2010). The pooled analysis showed no statistically significant difference in the proportion of patients who experienced a serious adverse event. Eleven per cent (10/88) of patients in the antimetabolite group experienced an adverse event compared to $1 \%(1 / 81)$ of patients in the 5 -aminosalicylates group (RR 2.61, 95\% CI 0.04 to 162.02 ). A high degree of heterogeneity was detected for this comparison ( $\left.\mathrm{P}=0.05, \mathrm{I}^{2}=74 \%\right)$.

Commonly reported adverse events included leucopenia ( Ardizzone 2004; Hanauer 2004; Herfarth 2006; Reinisch 2010), arthralgia (Hanauer 2004; Herfarth 2006; Reinisch 2010; Savarino 2013), abdominal pain or severe epigastric intolerance (Ardizzone 2004; Herfarth 2006; Reinisch 2010; Savarino 2013), elevated liver enzymes (Ardizzone 2004; Hanauer 2004; Herfarth 2006), nausea and vomiting (Herfarth 2006; Reinisch 2010; Savarino 2013), pancreatitis (Ardizzone 2004; Herfarth 2006; Reinisch 2010), anaemia (Herfarth 2006; Reinisch 2010), exacerbation of Crohn's disease (Reinisch 2010; Savarino 2013), nasopharyngitis (Reinisch 2010; Savarino 2013), and flatulence (Hanauer 2004; Reinisch 2010).

Azathioprine and 6-mercaptopurine for maintenance of surgically-induced remission in Crohn's disease (Review) 


\section{Azathioprine versus infliximab}

\section{Efficacy}

One study with a total of 22 participants compared azathioprine to infliximab (Armuzzi 2013). There was no statistically significant difference in the proportion of patients who had a clinical relapse. Eighteen per cent $(2 / 11)$ of patients in the azathioprine group relapsed clinically compared to $9 \%(1 / 11)$ of infliximab patients (RR 2.00, 95\% CI 0.21 to 18.98). A GRADE analysis indicated that the overall quality of the evidence for this outcome was very low due to high risk of bias (the study was not blinded) and very sparse data (3 events, See Summary of findings 3). There was no statistically significant difference in the proportion of patients who had endoscopic relapse. Forty per cent (4/10) of patients in the azathioprine group relapsed endoscopically compared to $9 \%$ (1/ 11) of infliximab patients (RR 4.40, 95\% CI 0.59 to 33.07). A GRADE analysis indicated that the overall quality of the evidence for this outcome was very low due to high risk of bias (the study was not blinded) and very sparse data ( 5 events, See Summary of findings 3).

\section{Safety}

There was no statistically significant difference in the proportion of patients who withdrew due to adverse events. One patient in the azathioprine group $(1 / 11,9 \%)$ withdrew due to an adverse event (i.e. nausea and epigastric pain) compared to no patients in the infliximab group (RR 3.00, 95\% CI 0.14 to 66.53). No other adverse events were reported.

\section{Azathioprine versus adalimumab}

One study with a total of 33 participants compared azathioprine to adalimumab (Savarino 2013). There was a statistically significant difference in the proportion of patients who had a clinical relapse. Sixty-five per cent (11/17) of patients in the azathioprine group relapsed clinically compared to $12 \%(2 / 16)$ of adalimumab patients (RR 5.18, 95\% CI 1.35 to 19.83 ). A GRADE analysis indicated that the overall quality of the evidence for this outcome was very low due to high risk of bias (the study was not blinded) and very sparse data (13 events, See Summary of findings 4). There was a statistically significant difference in the proportion of patients who had endoscopic relapse. Sixty-five per cent (11/ 17) of patients in the azathioprine group relapsed endoscopically compared to $6 \%$ (1/16) of adalimumab patients (RR 10.35, 95\% CI 1.50 to 71.32 ). A GRADE analysis indicated that the overall quality of the evidence for this outcome was very low due to high risk of bias (the study was not blinded) and very sparse data (12 events, See Summary of findings 4).

\section{Safety}

Savarino 2013 reported on the proportion of patients who experienced at least one adverse event and on the proportion of patients who withdrew due to adverse events. There was no statistically significant difference in the proportion of patients who had an adverse event. Eight-eight per cent (15/17) had an adverse event compared to $69 \%$ (11/16) of adalimumab patients (RR $1.28,95 \%$ CI 0.88 to 1.86 ). There was no statistically significant difference in the proportion of patients who withdrew due to adverse events. Twelve per cent (2/17) of azathioprine patients withdrew due to an adverse event compared to $6 \%(1 / 16)$ of patients in the adalimumab group (RR $1.88,95 \%$ CI 0.19 to 18.80 ). Commonly reported adverse events included bronchitis, nasopharyngitis, flu, abdominal pain, nausea and vomiting, arthralgia, dermatitis, and abscess (Savarino 2013).

\section{Efficacy}


ADDITIONALSUMMARY OF FINDINGS [Explanation]

Azathioprine (AZA) or 6-mercaptopurine (6-MP) versus 5-aminosalicylic acid (5-ASA) for maintenance of surgically-induced remission in Crohn's disease

Patient or population: Patients in remission after surgery for Crohn's disease

Settings: Outpatient

Intervention: AZA or 6-MP versus 5-ASA

\begin{tabular}{|c|c|c|c|c|c|c|}
\hline \multirow[t]{3}{*}{ Outcomes } & \multicolumn{2}{|c|}{ Illustrative comparative risks* (95\% CI) } & \multirow{3}{*}{$\begin{array}{l}\text { Relative effect } \\
(95 \% \mathrm{CI})\end{array}$} & \multirow{3}{*}{$\begin{array}{l}\text { No of Participants } \\
\text { (studies) }\end{array}$} & \multirow{3}{*}{$\begin{array}{l}\text { Quality of the evidence } \\
\text { (GRADE) }\end{array}$} & \multirow[t]{3}{*}{ Comments } \\
\hline & Assumed risk & Corresponding risk & & & & \\
\hline & Control & $\begin{array}{l}\text { AZA or } 6 \text {-MP versus } 5 \text { - } \\
\text { ASA }\end{array}$ & & & & \\
\hline Clinical relapse & 541 per $1000^{1}$ & $\begin{array}{l}\mathbf{6 2 2} \text { per } 1000 \\
\text { (536 to } 725)\end{array}$ & $\begin{array}{l}\text { RR } 1.15 \\
(0.99 \text { to } 1.34)\end{array}$ & $\begin{array}{l}425 \\
\text { (5 studies) }\end{array}$ & $\begin{array}{l}\oplus \bigcirc \bigcirc \bigcirc \\
\text { very low } \mathbf{w}^{2,3,4}\end{array}$ & \\
\hline $\begin{array}{l}\text { Clinical relapse (sensi- } \\
\text { tivity analysis excluding } \\
\text { study that enrolled pa- } \\
\text { tients with endoscopic } \\
\text { recurrence) }\end{array}$ & 594 per $1000^{1}$ & $\begin{array}{l}630 \text { per } 1000 \\
(540 \text { to } 737)\end{array}$ & $\begin{array}{l}\text { RR } 1.06 \\
\text { (0.91 to 1.24) }\end{array}$ & $\begin{array}{l}347 \\
\text { (4 studies) }\end{array}$ & $\begin{array}{l}\oplus \oplus \bigcirc \bigcirc \\
\mathbf{l}_{\mathbf{0}} \mathbf{w}^{2,5}\end{array}$ & \\
\hline $\begin{array}{l}\text { Clinical relapse (sub- } \\
\text { group analysis - AZA } \\
\text { studies only) }\end{array}$ & 485 per $1000^{1}$ & $\begin{array}{l}606 \text { per } 1000 \\
(504 \text { to } 732)\end{array}$ & $\begin{array}{l}\text { RR } 1.25 \\
\text { (1.04 to } 1.51)\end{array}$ & $\begin{array}{l}334 \\
\text { (4 studies) }\end{array}$ & $\begin{array}{l}\oplus \oplus \bigcirc \bigcirc \\
\mathbf{l}_{\mathbf{0}} \mathbf{w}^{2,6}\end{array}$ & \\
\hline $\begin{array}{l}\text { Endoscopic relapse } \\
\text { (AZA study) }\end{array}$ & 833 per $1000^{1}$ & $\begin{array}{l}650 \text { per } 1000 \\
(433 \text { to } 975)\end{array}$ & $\begin{array}{l}\text { RR } 0.78 \\
(0.52 \text { to } 1.17)\end{array}$ & $\begin{array}{l}35 \\
\text { (1 study) }\end{array}$ & $\begin{array}{l}\oplus \bigcirc \bigcirc \bigcirc \\
\text { very low }\end{array}$ & \\
\hline $\begin{array}{l}\text { Endoscopic relapse (6- } \\
\text { MP study) }\end{array}$ & 477 per $1000^{1}$ & $\begin{array}{l}172 \text { per } 1000 \\
(86 \text { to } 343)\end{array}$ & $\begin{array}{l}\text { RR } 0.36 \\
(0.18 \text { to } 0.72)\end{array}$ & $\begin{array}{l}91 \\
\text { (1 study) }\end{array}$ & $\begin{array}{l}\oplus \oplus \bigcirc \bigcirc \\
\text { low }^{9}\end{array}$ & \\
\hline
\end{tabular}

*The basis for the assumed risk (e.g. the median control group risk across studies) is provided in footnotes. The corresponding risk (and its $95 \%$ confidence interval) is based on the assumed risk in the comparison group and the relative effect of the intervention (and its $95 \% \mathrm{Cl}$ ).

Cl: Confidence interval; RR: Risk ratio 
GRADE Working Group grades of evidence

High quality: Further research is very unlikely to change our confidence in the estimate of effect.

Moderate quality: Further research is likely to have an important impact on our confidence in the estimate of effect and may change the estimate.

Low quality: Further research is very likely to have an important impact on our confidence in the estimate of effect and is likely to change the estimate.

Very low quality: We are very uncertain about the estimate.

Control group risk estimates come from control arm of meta-analysis, based on included trials.

${ }^{2}$ High risk of bias in two studies in pooled analysis due to lack of blinding.

${ }^{3}$ Sparse data (249 events).

${ }^{4}$ Moderate heterogeneity $\mathrm{P}^{2}=45 \%$.

5 Sparse data (214 events).

${ }^{6}$ Sparse data (184 events).

7 High risk of bias due to lack of blinding

${ }^{8}$ Very sparse data (26 events) and wide confidence interval.

${ }^{9}$ Very sparse data (29 events) and wide confidence interval. 
Azathioprine (AZA) versus infliximab for maintenance of surgically-induced remission in Crohn's disease

Patient or population: Patients in remission after surgery for Crohn's disease

Settings: Outpatient

Intervention: AZA versus infliximab

\begin{tabular}{|c|c|c|c|c|c|c|}
\hline \multirow[t]{3}{*}{ Outcomes } & \multicolumn{2}{|c|}{ Illustrative comparative risks* $(95 \% \mathrm{Cl})$} & \multirow{3}{*}{$\begin{array}{l}\text { Relative effect } \\
(95 \% \text { CI })\end{array}$} & \multirow{3}{*}{$\begin{array}{l}\text { No of Participants } \\
\text { (studies) }\end{array}$} & \multirow{3}{*}{$\begin{array}{l}\text { Quality of the evidence } \\
\text { (GRADE) }\end{array}$} & \multirow[t]{3}{*}{ Comments } \\
\hline & Assumed risk & Corresponding risk & & & & \\
\hline & Control & AZA versus infliximab & & & & \\
\hline Clinical relapse & 91 per $1000^{1}$ & $\begin{array}{l}\mathbf{1 8 2} \text { per } \mathbf{1 0 0 0} \\
\text { (19 to } 1727)\end{array}$ & $\begin{array}{l}\text { RR } 2.00 \\
\text { (0.21 to 18.98) }\end{array}$ & $\begin{array}{l}22 \\
\text { (1 study) }\end{array}$ & $\begin{array}{l}\oplus \bigcirc \bigcirc \bigcirc \\
\text { very low } 2,3\end{array}$ & \\
\hline Endoscopic relapse & 91 per $1000^{1}$ & $\begin{array}{l}400 \text { per } 1000 \\
(54 \text { to } 3009)\end{array}$ & $\begin{array}{l}\text { RR } 4.40 \\
\text { (0.59 to } 33.07)\end{array}$ & $\begin{array}{l}21 \\
\text { (1 study) }\end{array}$ & $\begin{array}{l}\oplus \bigcirc \bigcirc \bigcirc \\
\text { very low } 2,4\end{array}$ & \\
\hline
\end{tabular}

*The basis for the assumed risk (e.g. the median control group risk across studies) is provided in footnotes. The corresponding risk (and its $95 \%$ confidence interval) is based on the assumed risk in the comparison group and the relative effect of the intervention (and its $95 \% \mathrm{Cl}$ ).

CI: Confidence interval; RR: Risk ratio

GRADE Working Group grades of evidence

High quality: Further research is very unlikely to change our confidence in the estimate of effect.

Moderate quality: Further research is likely to have an important impact on our confidence in the estimate of effect and may change the estimate.

Low quality: Further research is very likely to have an important impact on our confidence in the estimate of effect and is likely to change the estimate.

Very low quality: We are very uncertain about the estimate.

${ }^{1}$ Control group risk estimates come from control arm of meta-analysis, based on included trial.

2 High risk of bias due to lack of blinding.

${ }^{3}$ Very sparse data ( 3 events) and very wide confidence interval.

${ }^{4}$ Very sparse data (5 events) and very wide confidence interval. 
Azathioprine (AZA) versus adalimumab for maintenance of surgically-induced remission in Crohn's disease

Patient or population: Patients in remission after surgery for Crohn's disease

Settings: Outpatient

Intervention: AZA versus adalimumab

\begin{tabular}{|c|c|c|c|c|c|c|}
\hline \multirow[t]{3}{*}{ Outcomes } & \multicolumn{2}{|c|}{ Illustrative comparative risks* $(95 \% \mathrm{Cl})$} & \multirow{3}{*}{$\begin{array}{l}\text { Relative effect } \\
\text { (95\% Cl) }\end{array}$} & \multirow{3}{*}{$\begin{array}{l}\text { No of Participants } \\
\text { (studies) }\end{array}$} & \multirow{3}{*}{$\begin{array}{l}\text { Quality of the evidence } \\
\text { (GRADE) }\end{array}$} & \multirow[t]{3}{*}{ Comments } \\
\hline & Assumed risk & Corresponding risk & & & & \\
\hline & Control & AZA versus adalimumab & & & & \\
\hline Clinical relapse & 125 per $1000^{1}$ & $\begin{array}{l}\mathbf{6 4 8} \text { per } \mathbf{1 0 0 0} \\
\text { (169 to } 2479)\end{array}$ & $\begin{array}{l}\text { RR } 5.18 \\
\text { (1.35 to 19.83) }\end{array}$ & $\begin{array}{l}33 \\
\text { (1 study) }\end{array}$ & $\begin{array}{l}\oplus \bigcirc \bigcirc \bigcirc \\
\text { very low } 2,3\end{array}$ & \\
\hline $\begin{array}{l}\text { Endoscopic relapse (6- } \\
\text { MP study) }\end{array}$ & 62 per $1000^{1}$ & $\begin{array}{l}\mathbf{6 4 2} \text { per } 1000 \\
(93 \text { to } 4422)\end{array}$ & $\begin{array}{l}\text { RR 10.35 } \\
\text { (1.50 to } 71.32)\end{array}$ & $\begin{array}{l}33 \\
\text { (1 study) }\end{array}$ & $\begin{array}{l}\oplus \bigcirc \bigcirc \bigcirc \\
\text { very low } 2,4\end{array}$ & \\
\hline
\end{tabular}

*The basis for the assumed risk (e.g. the median control group risk across studies) is provided in footnotes. The corresponding risk (and its $95 \%$ confidence interval) is based on the assumed risk in the comparison group and the relative effect of the intervention (and its $95 \% \mathrm{Cl}$ ).

Cl: Confidence interval; RR: Risk ratio

GRADE Working Group grades of evidence

High quality: Further research is very unlikely to change our confidence in the estimate of effect.

Moderate quality: Further research is likely to have an important impact on our confidence in the estimate of effect and may change the estimate.

Low quality: Further research is very likely to have an important impact on our confidence in the estimate of effect and is likely to change the estimate.

Very low quality: We are very uncertain about the estimate.

${ }^{1}$ Control group risk estimates come from control arm of meta-analysis, based on included trial.

2 High risk of bias due to lack of blinding.

${ }^{3}$ Very sparse data (13 events) and very wide confidence interval.

${ }^{4}$ Very sparse data (12 events) and very wide confidence interval. 


\section{DISCUSSION}

\section{Summary of main results}

The Hanauer 2004 and D'Haens 2008 studies compared azathioprine or 6-mercaptopurine to placebo, with meta-analysis suggesting the superiority of purine analogues over placebo for preventing clinical (2 studies, 168 patients) and endoscopic relapse (1 study, 87 patients). This small evidence base gives some support for the use of purine analogues for maintenance of surgically-induced remission in CD.

However, meta-analysis of five studies ( $\mathrm{n}=425$ patients) comparing purine analogues to 5-aminosalicylic acid found no statistically significant differences in clinical relapse rates (Ardizzone 2004; Hanauer 2004; Herfarth 2006; Reinisch 2010; Savarino 2013). A subgroup analysis by drug type suggests that azathioprine may be significantly inferior to 5-aminosalicylic acid. Sixty-one per cent of azathioprine patients had a clinical relapse compared to $48 \%$ of 5-aminosalicylic acid patients (RR 1.25, 95\% CI 1.04 to 1.51 ). There was no statistically significant difference in clinical relapse rates between 6-mercaptopurine and 5-aminosalicylic acid. However, clinical heterogeneity among the pooled studies was a concern. Reinisch 2010 enrolled patients with active endoscopic recurrence within 6 to 24 months of surgery, whereas the patients in the other three studies were enrolled within two weeks of surgery and were unlikely to have endoscopic recurrence. A sensitivity analysis excluding the Reinisch 2010 study found no statistically significant difference between azathioprine and 5-aminosalicyclic acid. A subgroup analysis by length of follow-up suggests a statistically significant benefit for 5-aminosalicylates over purine analogues at 12 months but not at 24 months. Seventy-six per cent of patients in the antimetabolite group experienced a clinical relapse at 12 months compared to $54 \%$ of 5 -aminosalicylate patients (RR $1.40,95 \%$ CI 1.12 to $1.74 ; 2$ studies, 157 patients). However, a high degree of heterogeneity was detected for this comparison ( $\mathrm{P}$ $\left.=0.04, \mathrm{I}^{2}=77 \%\right)$. A sensitivity analysis removing the Reinisch 2010 study found no statistically significant difference in clinical relapse rates between purine analogues and 5-aminosalicyclic acid at 12 months follow-up.

There are considerable concerns raised with the safety profile of azathioprine and 6-mercaptopurine. Adverse events requiring medication to be discontinued were significantly more common in the purine analogue group compared to 5-aminosalicylic acid. One small study $(\mathrm{n}=22)$ compared azathioprine to infliximab and found no statistically significant differences in clinical relapse, endoscopic relapse or withdrawal due to adverse events (Armuzzi 2013). Savarino $2013(\mathrm{n}=33$ ) compared azathioprine to adalimumab and found statistically significant differences in clinical and endoscopic relapse favouring adalimumab over azathioprine. The results of these studies should be interpreted with caution due to the small number of patients.

\section{Overall completeness and applicability of}

\section{evidence}

We consider the evidence from this review to be applicable to most patients with post-surgical remission of CD. However, the evidence base cannot be considered to be complete. This review has found a relatively small evidence base for the use of purine analogues in the maintenance of surgically-induced remission in CD, despite the widespread use of such medications in this setting. The two studies ( $\mathrm{n}=168$ participants) comparing azathioprine or 6mercaptopurine with placebo had significant clinical and methodological heterogeneity regarding the choice of purine analogue and the use of concurrent medications. There was considerable clinical and methodological heterogeneity across the five studies ( $n=425$ patients) that compared azathioprine or 6-mercaptopurine to 5aminosalicylic acid. Most of the trials were relatively small and probably lacked sufficient power to detect any differences between intervention groups. One small study compared azathioprine to infliximab $(n=22)$ and one small study compared azathioprine to adalimumab. Therefore, the evidence base can clearly be seen as lacking.

\section{Quality of the evidence}

Four studies were judged to be at high risk of bias for blinding due to open-label (Ardizzone 2004; Armuzzi 2013; Savarino 2013), and single-blind design (D'Haens 2008). The results of the included studies need to be interpreted with caution as GRADE analyses rated the overall quality of the evidence for the primary outcomes (i.e. clinical relapse or endoscopic relapse) as low or very low due to high risk of bias (i.e. open-label or single-blind studies), heterogeneity and imprecision (i.e. very sparse data) (See Summary of findings 2; Summary of findings for the main comparison; Summary of findings 3; Summary of findings 4).

\section{Potential biases in the review process}

We attempted to reduce potential biases in the review process. A comprehensive literature search was performed to identify all eligible studies. Two review authors independently assessed studies for inclusion, extracted data and assessed study quality.

All analyses were completed using the intention-to-treat principle, whereby patients with final missing outcomes were assumed to have relapsed. Given the high attrition rate in the purine analogue groups compared to the 5-aminosalicylate groups, this may have affected the difference in clinical relapse rates between purine analogues and 5-aminosalicylates. However, it is arguably a moot point given that even if purine analogues do have superior efficacy, it is difficult to rationalise the use on the basis of the poor adverse event profile in the published evidence.

\section{Agreements and disagreements with other studies or reviews}


A recent Cochrane review assessing the use of azathioprine or 6mercaptopurine for maintenance of medically-induced remission in CD disease revealed that the purine analogues are more effective than placebo, with higher response rates for azathioprine than 6mercaptopurine (Prefontaine 2009). These findings are mirrored in the two studies comparing purine analogues to placebo. No difference in efficacy was found between azathioprine or 6-mercaptopurine and 5-aminosalicylic acid. This could be due to lower disease activity following resection of the gut than is achieved in medically-induced remission of CD, so that a milder anti-inflammatory agent such as 5-aminosalicylic acid, gives a better risk versus benefit ratio when compared to azathioprine and 6-mercaptopurine. It is also possible that the methodology of the included studies supports this hypothesis, with all but one study recruiting patients in the immediate post-surgical setting. As such, the patients are potentially at their lowest period of disease activity clinically and microscopically.

A Cochrane review (Gordon 2011) looking at the use of 5-aminosalicylic acid for the maintenance of surgically-induced remission in $\mathrm{CD}$ suggests that 5-aminosalicyclic acid may be superior to placebo (Gordon 2011). It also showed that 5-aminosalicylic acid is a safe and well tolerated drug, as the incidence of adverse events was not different in patients receiving 5-aminosalicylic acid compared to those receiving placebo. The results of this systematic review question the risk versus benefit balance of starting a purine analogue over 5-aminosalicylic acid in postoperative CD.

\section{AUTHORS, CONCLUSIONS}

\section{Implications for practice}

Purine analogues may be superior to placebo for maintenance of surgically-induced remission in patients with CD. The results for efficacy outcomes between purine analogues and 5-aminosalicylic acid were uncertain. However, patients taking purine analogues were more likely than 5-aminosalicylic acid patients to discontinue therapy due to adverse events. These results question the use of azathioprine and 6-mercaptopurine in patients with surgically- induced remission of CD. No firm conclusions can be drawn from the two small studies that compared azathioprine to infliximab or adalimumab. Adalimumab may be superior to azathioprine but further research is needed to confirm these results. There may be a role for other agents for maintenance of post-surgical remission in CD.

\section{Implications for research}

Using the GRADE criteria the overall quality of the evidence was judged to be low for the placebo controlled studies and low or very low for the active comparator studies. Therefore the strength of our conclusions is extremely limited. Further research investigating the efficacy and safety of azathioprine and 6-mercaptopurine in comparison to other active medications in patients with surgically-induced remission of CD is warranted. The use of TPMT monitoring as part of such research protocols may be beneficial. Only one of the five studies mentioned the use of TPMT monitoring which may be important in identifying patients who are more likely to tolerate azathioprine and 6-mercaptopurine. There could be a role for TMPT monitoring when weighing the risk versus benefit of using purine analogues, and future research could incorporate this.

\section{ACKNOWLEDGEMENTS}

Funding for the IBD/FBD Review Group (September 1, 2010 to August 31, 2015) has been provided by the Canadian Institutes of Health Research (CIHR) Knowledge Translation Branch (CON - 105529) and the CIHR Institutes of Nutrition, Metabolism and Diabetes (INMD); and Infection and Immunity (III) and the Ontario Ministry of Health and Long Term Care (HLTC3968FL2010-2235).

Miss Ila Stewart has provided support for the IBD/FBD Review Group through the Olive Stewart Fund.

The authors would like to thank Drs. P Nos, Hans Herfarth and Geert D'Haens for providing additional information on their studies. 


\section{R E F E R E N C E S}

\section{References to studies included in this review}

\section{Ardizzone 2004 \{published data only\}}

Ardizzone S, Maconi G, Sampietro GM, Russo A, Radice

E, Colombo E, et al. Azathioprine and mesalamine for prevention of relapse after conservative surgery for Crohn's disease. Gastroenterology 2004;127(3):730-40.

Armuzzi 2013 \{published data only\}

Armuzzi A, Felice C, Marzo M, Pugliese D, Andrisani G, Papa A, et al. Prevention of postoperative recurrence with azathioprine or anti-TNF alpha in patients with Crohn's disease: A pilot study. Digestive and Liver Disease 2012;44: S194.

Armuzzi A, Felice C, Marzo M, Pugliese D, Andrisani G, Papa A, et al. Prevention of postoperative recurrence with azathioprine or anti-TNF alpha in patients with Crohn's disease: An open-label pilot study. Gastroenterology 2012; 142(5 Suppl 1):S780.

* Armuzzi A, Felice C, Papa A, Marzo M, Pugliese D, Andrisani G, et al. Prevention of postoperative recurrence with azathioprine or infliximab in patients with Crohn's disease: an open-label pilot study. Journal of Crohn's and Colitis 2013;7(12):e623-9.

D’Haens 2008 \{published data only\}

* D'Haens G, Vermeire S, Van Assche G, Noman M, Aerden I, Van Olmen G, et al. Therapy of metronidazole with azathioprine to prevent postoperative recurrence of Crohn's disease: a controlled randomized trial. Gastroeneterology 2008;135(4):1123-9.

D’Haens GR, Noman M, Van Assche GA, Van Olmen G, Aerden I, Vermeire S, et al. Combination therapy with metronidazole and azathioprine reduces severe postoperative recurrence of Crohn's disease: A double-blind controlled randomized trial. Gastroenterology 2007;132(4 Suppl 1): A52.

Hanauer 2004 \{published data only\}

* Hanauer SB, Korelitz BI, Rutgeerts P, Peppercorn MA,

Thisted RA, Cohen RD, et al. Postoperative maintenance of Crohn's disease remission with 6-mercaptopurine, mesalamine or placebo: a 2-year trial. Gastroenterology 2004; 127(3):723-9.

Korelitz B, Hanauer S, Rutgeerts P, Present D, Peppercorn M. Post-operative prophylaxis with 6-MP, 5-ASA or placebo in Crohn's disease: A 2 year multicenter trial. Gastroenterology 1998;114(4 Part 2):A486.

Herfarth 2006 \{published data only (unpublished sought but not used)\} Dilger K, Schaeffeler E, Lukas M, Strauch U, Herfarth H, Muller R, et al. Monitoring of thiopurine methyltransferase activity in postsurgical patients with Crohn's disease during 1 year of treatment with azathioprine or mesalazine. Therapeutic Drug Monitoring 2007;29(1):1-5. Herfarth H, Obermeier F, Tjaden C, Lukas M, Serclova $Z$, Dignass AU, et al. Double-blind, double dummy, randomized, multicentre, comparative study on the efficacy and safety of azathioprine (AZA) versus mesalazine (5-
ASA) for prevention of postoperative endoscopic recurrence in Crohn's disease. Gastroenterology 2006;130(4 Suppl 2): A480-1.

* Herfarth H, Tjaden C, Lukas M, Obermeier F, Dilger $\mathrm{K}$, Muller R, et al. Adverse events in clinical trials with azathioprine and mesalamine for the prevention of postoperative recurrence of Crohn's disease. Gut 2006;55 (10):1525-6.

Reinisch 2010 \{published data only\}

Angelberger S, Schaeffeler E, Teml A, Petritsch W, Shonova $\mathrm{O}$, Lukas $\mathrm{M}$, et al. Mucosal improvement in patients with moderate to severe postoperative endoscopic recurrence of Crohn's disease and azathioprine metabolite levels. Inflammatory Bowel Diseases 2013;19(3):590-8.

Angelberger S, Schaeffeler E, Teml A, Petritsch W, Shonova $\mathrm{O}$, Lukas M, et al. Relationship between thiopurine metabolite levels and endoscopic improvement in patients with postoperative moderate to severe endoscopic recurrence of Crohn's disease. Gastroenterology 2010;138(5 Suppl 1): S685.

Reinisch W, Angelberger S, Petritsch W, Herrlinger K, Shonova O, Lukas $\mathrm{M}$, et al. A double-blind, doubledummy, randomized, controlled, multicenter trial on the efficacy and safety of azathioprine vs mesalamine for prevention of clinical relapses in Crohn's disease patients with postoperative moderate or severe endoscopic recurrence. Gastroenterology 2008;134(4 Suppl 1):A70. ${ }^{*}$ Reinisch W, Angelberger S, Petritsch W, Shonova O, Lukas M, Bar-Meir S, et al. Azathioprine versus mesalazine for the prevention of postoperative clinical recurrence in patients with Crohn's disease with endoscopic recurrence: efficacy and safety results of a randomized, double-blind, double-dummy, multicentre trial. Gut 2010;59(6):752-9. Reinisch W, Angelberger S, Petritsch W, Shonova O, Lukas M, Greinwald R, et al. Azathioprine versus mesalazine for prevention of postoperative clinical recurrence in Crohn's disease patients with endoscopic recurrence: Follow-up data of a randomised, double-blind, double-dummy, 1-year, multicentre trial. Journal of Crohn's and Colitis 2013;7:S254. Reinisch W, Stange EF. Efficacy of azathioprine versus mesalazine in postoperative Crohn's disease - the authors' response. Gut 2011;60(5):739-40.

Savarino 2013 \{published data only\} Savarino E, Bodini G, Dulbecco P, Assandri L, Bruzzone L, Mazza F. Adalimumab is more effective than azathioprine and mesalamine at preventing postoperative recurrence of Crohn's disease - a randomized trial. Digestive and Liver Disease 2013;45:S94-5.

* Savarino E, Bodini G, Dulbecco P, Assandri L, Bruzzone L, Mazza F, et al. Adalimumab is more effective than azathioprine and mesalamine at preventing postoperative recurrence of Crohn's disease: a randomized controlled trial. American Journal of Gastroenterology 2013;108(11): 1731-42.

Savarino E, Bodini G, Dulbecco P, Marabotto E, Assandri L, 
Bruzzone L. Adalimumab is more effective than azathioprine and mesalamine at preventing postoperative recurrence of Crohn's disease - a randomized trial. Gastroenterology 2013; 144(5 Suppl 1):S21.

\section{References to studies excluded from this review}

\section{Ferrante 2014 \{published data only\}}

Ferrante M, Papamichael K, Duricova D, D'Haens G, Vermeire S, Archavlis E, et al. Systematic versus endoscopydriven treatment with azathioprine to prevent postoperative ileal Crohn's disease recurrence. Journal of Crohn's and Colitis 2014;8:S205-6.

\section{Mañosa 2013 \{published data only\}}

Manosa M, Cabre E, Bernal I, Esteve M, Garcia- Planella E, Ricart Gomez E. Azathioprine versus azathioprine plus metronidazole for the prevention of postoperative endoscopic recurrence of Crohn's disease: A randomized, placebo-controlled trial. Journal of Crohn's and Colitis 2012; 6:S93.

* Mañosa M, Cabré E, Bernal I, Esteve M, Garcia-Planella E, Ricart E, et al. Addition of metronidazole to azathioprine for the prevention of postoperative recurrence of Crohn's disease: a randomized, double-blind, placebo-controlled trial. Inflammatory Bowel Diseases 2013;19(9):1889-95.

Nos 2000 \{published data only\}

Nos P, Hinojosa J, Aguilera V, Moles JR, Pastor $\mathrm{M}$, Ponce J, et al. Azathiprine and 5-ASA in the prevention of postoperative recurrence in Crohn's disease. Gastroenterología y Hepatología 2000;23(8):374-8.

\section{Additional references}

Benchimol 2009

Benchimol EI, Seow CH, Otley AR, Steinhart AH. Budesonide for maintenance of remission in Crohn's disease. Cochrane Database of Systematic Reviews 2009, Issue 1. [DOI: 10.1002/14651858.CD002913.pub2]

Bernell 2000

Bernell O, Lapidus A, Hellers G. Risk factors for surgery and postoperative recurrence in Crohn's disease. Annals of Surgery 2000;231(1):38-45.

\section{Colonna 1994}

Colonna T, Korelitz BI. The role of leukopenia in the 6mercaptopurine induced remission of refractory Crohn's disease. American Journal of Gastroenterology 1994;89(3): 362-6.

\section{Doherty 2009}

Doherty G, Bennett G, Patil S, Cheifetz A, Moss AC. Interventions for prevention of post-operative recurrence of Crohn's disease. Cochrane Database of Systematic Reviews 2009, Issue 4. [DOI: 10.1002/ 14651858.CD006873.pub2]

\section{Gordon 2011}

Gordon M, Naidoo K, Thomas AG, Akobeng AK. Oral 5 -aminosalicylic acid for maintenance of surgicallyinduced remission in Crohn's disease. Cochrane Database of Systematic Reviews 2011, Issue 1. [DOI: 10.1002/

14651858.CD008414.pub2]

Guyatt 2008

Guyatt GH, Oxman AD, Vist GE, Kunz R, Falck-Ytter Y, Alonso-Coello P, et al. GRADE: an emerging consensus on rating quality of evidence and strength of recommendations. BMJ 2008;336(7650):924-6.

Hafraoui 2002

Hafraoui S, Dewit O, Marteau P, Cosnes J, Colombel JF, Modigliani R, et al. Mycophenolate mofetil in refractory Crohn's disease after failure of treatments by azathioprine or methotrexate [Le mycophénolate mofétil dans les formes chroniques actives de la maladie de Crohn après échec de lazathioprine ou du méthotrexate]. Gastroenterologie Clinique et Biologique 2002;26(1):17-22.

\section{Hanauer 2001}

Hanauer SB, Sandborn W. Management of Crohn's disease in adults. American Journal of Gastroenterology 2001;96(3): $635-43$.

\section{Higgins 2003}

Higgins JP, Thompson SG, Deeks JJ, Altman DG. Measuring inconsistency in meta-analyses. BMJ 2003;327 (7414):557-60.

\section{Higgins 2011}

Higgins JPT, Altman DG, Sterne JAC (editors). Chapter 8: Assessing risk of bias in included studies. In: Higgins JPT, Green S editor(s). Cochrane Handbook for Systematic Reviews of Interventions Version 5.1.0 (updated March 2011). The Cochrane Collaboration, 2011. Available from www.cochrane-handbook.org.

\section{Pitkin 1999}

Pitkin RM, Branagan MA, Burmeister LF. Accuracy of data in abstracts of published research articles. JAMA 1999;281 (12):1110-1.

\section{Prefontaine 2009}

Prefontaine E, Sutherland LR, Macdonald JK, Cepoiu M. Azathioprine or 6-mercaptopurine for maintenance of remission in Crohn's disease. Cochrane Database of Systematic Reviews 2009, Issue 1. [DOI: 10.1002/ 14651858.CD000067.pub2]

\section{Regueiro 2009}

Regueiro M, Schraut W, Baidoo L, Kip KE, Sepulveda $\mathrm{AR}$, Pasci $\mathrm{M}$, et al. Infliximab prevents Crohn's disease recurrence after ileal resection. Gastroenterology 2009;136 (2):441-50.

\section{RevMan 2014}

The Nordic Cochrane Centre, The Cochrane Collaboration. Review Manager (RevMan). 5.3. Copenhagen: The Nordic Cochrane Centre, The Cochrane Collaboration, 2014.

\section{Rolfe 2006}

Rolfe VE, Fortun PJ, Hawkey CJ, Bath-Hextall FJ. Probiotics for maintenance of remission in Crohn's disease. Cochrane Database of Systematic Reviews 2006, Issue 4. [DOI: 10.1002/14651858.CD004826.pub2] 


\section{Rutgeerts 1990}

Rutgeerts P, Geboes K, Vantrappen G, Beyls J, Kerremans R, Hiele M. Predictability of the postoperative course of Crohn's disease. Gastroenterology 1990;99(4):956-63.

\section{Schünemann 2011}

Schünemann HJ, Oxman AD, Vist GE, Higgins JPT, Deeks JJ, Glasziou P, et al. Chapter 12: Interpreting results and drawing conclusions. In: Higgins JPT, Green S editor(s). Cochrane Handbook for Systematic Reviews of Interventions Version 5.1.0 (updated March 2011).

The Cochrane Collaboration, 2011. Available from www.cochrane-handbook.org.

\section{Steinhart 2003}

Steinhart AH, Ewe K, Griffiths AM, Modigliani R,

Thomsen OO. Corticosteroids for maintenance of remission in Crohn's disease. Cochrane Database of Systematic Reviews 2003, Issue 4. [DOI: 10.1002/14651858.CD000301]

\section{Williams 1990}

Williams JG, Wong WD, Rothenberger DA, Goldberg SM. Recurrence of Crohn's disease after resection. British Journal of Surgery 1990;78(1):10-9.

* Indicates the major publication for the study 


\section{CHARACTERISTICS OF STUDIES}

\section{Characteristics of included studies [ordered by study ID]}

\section{Ardizzone 2004}

\begin{tabular}{|c|c|c|}
\hline Methods & \multicolumn{2}{|c|}{ Open-label, single-centre, randomised, controlled trial } \\
\hline Participants & \multicolumn{2}{|c|}{$\begin{array}{l}\text { Crohn's disease patients were enrolled } 2 \text { weeks after elective stricturoplasty, minimal } \\
\text { bowel resection or both }(\mathrm{N}=142) \\
\text { Exclusion criteria included contraindications for use of azathioprine or mesalamine; sig- } \\
\text { nificant preexisting conditions; the use of immunosuppressive drugs in the past } 3 \text { months } \\
\text { or anti-tumour necrosis factor within the } 6 \text { months before surgery; any corticosteroid- } \\
\text { dependant disease; as well as women who were pregnant, planning pregnancy or breast- } \\
\text { feeding }\end{array}$} \\
\hline Interventions & \multicolumn{2}{|c|}{$\begin{array}{l}\text { Azathioprine } 2 \mathrm{mg} / \mathrm{kg} / \text { day }(\mathrm{n}=71) \text { for } 24 \text { months or until relapse } \\
\text { Mesalamine } 3 \mathrm{~g} / \text { day }(\mathrm{n}=71) \text { for } 24 \text { months or until relapse }\end{array}$} \\
\hline Outcomes & \multicolumn{2}{|c|}{$\begin{array}{l}\text { Primary outcomes: clinical relapse (symptoms of active disease with laboratory, radio- } \\
\text { logical or endoscopic findings and CDAI }>200 \text { to warrant steroids) or surgical relapse } \\
\text { (symptoms refractory to medical treatment and need for further surgery) at } 24 \text { months } \\
\text { Secondary outcome: adverse events }\end{array}$} \\
\hline \multicolumn{3}{|l|}{ Notes } \\
\hline \multicolumn{3}{|l|}{ Risk of bias } \\
\hline Bias & Authors' judgement & Support for judgement \\
\hline $\begin{array}{l}\text { Random sequence generation (selection } \\
\text { bias) }\end{array}$ & Low risk & $\begin{array}{l}\text { Computer-generated randomisation in } \\
\text { blocks of } 10\end{array}$ \\
\hline Allocation concealment (selection bias) & Unclear risk & Not clearly described \\
\hline $\begin{array}{l}\text { Blinding of participants and personnel } \\
\text { (performance bias) } \\
\text { All outcomes }\end{array}$ & High risk & Open label study \\
\hline $\begin{array}{l}\text { Incomplete outcome data (attrition bias) } \\
\text { All outcomes }\end{array}$ & Unclear risk & Unclear with data reported \\
\hline Selective reporting (reporting bias) & Unclear risk & Unclear with data reported \\
\hline Other bias & Low risk & None apparent \\
\hline
\end{tabular}


Methods

Participants
Open-label, single-centre, randomised, controlled pilot study

Consecutive Crohn's disease patients who underwent a curative ileocolonic resection and were considered to be at 'high risk' of postoperative recurrence $(\mathrm{N}=22)$

Exclusion criteria: active perianal disease, presence of stoma, adverse events during previous therapy with infliximab or azathioprine, age $>70$ years, surgical complications, active infectious diseases, history of cancer, renal, cardiac or hepatic failure, history of acute or chronic

pancreatitis, severe leucopenia and pregnancy

Interventions

Infliximab $5 \mathrm{mg} / \mathrm{kg}$ at weeks 0,2 and 6 weeks and then every 8 weeks for 1 year $(\mathrm{n}=11)$ Azathioprine $2.5 \mathrm{mg} / \mathrm{kg} /$ day for 1 year $(\mathrm{n}=11)$

All patients received oral metronidazole (500 mg twice daily) for 2 weeks after surgery Treatment was started within 2 to 4 weeks of surgery

No other drugs were allowed

Outcomes

Co-primary outcomes were endoscopic, histological and clinical recurrence at 12 months Secondary outcomes: Harvey-Bradshaw Index, laboratory tests and adverse events

Notes

Risk of bias

\begin{tabular}{|c|c|c|}
\hline Bias & Authors' judgement & Support for judgement \\
\hline $\begin{array}{l}\text { Random sequence generation (selection } \\
\text { bias) }\end{array}$ & Unclear risk & Not described \\
\hline Allocation concealment (selection bias) & Unclear risk & Not described \\
\hline $\begin{array}{l}\text { Blinding of participants and personnel } \\
\text { (performance bias) } \\
\text { All outcomes }\end{array}$ & High risk & Open-label \\
\hline $\begin{array}{l}\text { Incomplete outcome data (attrition bias) } \\
\text { All outcomes }\end{array}$ & Low risk & $\begin{array}{l}\text { One patient in the azathioprine group } \\
\text { withdrew due to adverse events (severe nau- } \\
\text { sea and epigastric pain), no other patients } \\
\text { withdrew }\end{array}$ \\
\hline Selective reporting (reporting bias) & Low risk & Appropriate data reported \\
\hline Other bias & Low risk & None apparent \\
\hline
\end{tabular}




\begin{tabular}{|c|c|c|}
\hline Methods & \multicolumn{2}{|c|}{ Randomised controlled trial at 2 centres } \\
\hline Participants & \multicolumn{2}{|c|}{$\begin{array}{l}\text { Adult CD patients were enrolled within } 2 \text { weeks of curative ileal or ileocolonic resection } \\
\text { with ileocolonic anastomosis }(\mathrm{N}=81) \\
\text { Exclusion criteria: Patients with macroscopic evidence of pancolitis or disease proximal } \\
\text { or distal to the site of resection or those who had an ileorectal anastomosis or stoma, } \\
\text { contraindications for use of azathioprine or metronidazole; alcohol or drug abuse, leu- } \\
\text { copenia, malignancies or ongoing infectious disease (hepatitis, tuberculosis, AIDS); the } \\
\text { use of azathioprine within } 2 \text { months of surgery and pregnancy }\end{array}$} \\
\hline Interventions & \multicolumn{2}{|c|}{$\begin{array}{l}\text { Azathioprine } 100 \mathrm{mg} / \text { day if patient weight was }<60 \mathrm{~kg} \text { or } 150 \mathrm{mg} / \text { day if patient weight } \\
\text { was }>60 \mathrm{~kg}(\mathrm{n}=40) \text { for } 12 \text { months }(\mathrm{n}=40) \\
\text { Placebo for } 12 \text { months }(\mathrm{n}=41) \\
\text { All patients received metronidazole } 250 \mathrm{mg} \text { three times daily or ornidazole } 500 \mathrm{mg} \text { twice } \\
\text { daily for } 3 \text { months }\end{array}$} \\
\hline Outcomes & \multicolumn{2}{|c|}{$\begin{array}{l}\text { Primary outcome: proportion of patients with endoscopic recurrence ( }>2 \text { Rutgeers } \\
\text { endoscopic score) at } 3 \text { and } 12 \text { months } \\
\text { Secondary outcomes: clinical relapse (CDAI }>250 \text { ), the severity of endoscopic recurrence } \\
\text { and adverse events }\end{array}$} \\
\hline \multicolumn{3}{|l|}{ Notes } \\
\hline \multicolumn{3}{|l|}{ Risk of bias } \\
\hline Bias & Authors' judgement & Support for judgement \\
\hline $\begin{array}{l}\text { Random sequence generation (selection } \\
\text { bias) }\end{array}$ & Low risk & Computer-generated randomisation \\
\hline Allocation concealment (selection bias) & Low risk & Centralized pharmacy randomisation \\
\hline $\begin{array}{l}\text { Blinding of participants and personnel } \\
\text { (performance bias) } \\
\text { All outcomes }\end{array}$ & High risk & $\begin{array}{l}\text { Single-blind: azathioprine dummy was pro- } \\
\text { vided in sealed containers so the investigator } \\
\text { did not see the pills }\end{array}$ \\
\hline $\begin{array}{l}\text { Incomplete outcome data (attrition bias) } \\
\text { All outcomes }\end{array}$ & Low risk & Full data reported \\
\hline Selective reporting (reporting bias) & Low risk & Appropriate data reported \\
\hline Other bias & Low risk & None apparent \\
\hline
\end{tabular}


Hanauer 2004

Methods

Participants

Outcomes

Randomised, multi-centre double-blind, double-dummy, controlled trial

CD patients before postoperative hospital discharge after ileocolic resection with a primary anastomosis for disease confined to the ileum and adjacent colon $(\mathrm{N}=131)$

Patients were excluded if there was evidence of disease proximal or distal to the site of resection

$\begin{array}{ll}\text { Interventions } & \begin{array}{l}\text { 6-mercaptopurine } 50 \mathrm{mg} / \text { day for } 24 \text { months }(\mathrm{n}=47) \\ \text { mesalamine } 3 \mathrm{~g} / \text { day for } 24 \text { months }(\mathrm{n}=44) \\ \text { placebo for } 24 \text { months }(\mathrm{n}=40)\end{array}\end{array}$

Primary outcomes: clinical relapse (score of $>2$ on the clinical recurrence grading scale) at 6, 12 and 24 months, radiographic relapse (a score of $>2$ on the radiological recurrence grading scale) or endoscopic recurrence (score of $>2$ on the Rutgeerts endoscopic scoring system) at 12 and 24 months

Secondary outcome: adverse events

Notes

\section{Risk of bias}

\begin{tabular}{l|ll}
\hline Bias & Authors' judgement & Support for judgement \\
\hline $\begin{array}{l}\text { Random sequence generation (selection } \\
\text { bias) }\end{array}$ & Low risk & Computer randomisation in blocks of 6 \\
\hline $\begin{array}{l}\text { Allocation concealment (selection bias) } \\
\text { Blinding of participants and personnel } \\
\text { (performance bias) } \\
\text { All outcomes }\end{array}$ & Low risk & Centralized pharmacy randomisation \\
\hline $\begin{array}{l}\text { Incomplete outcome data (attrition bias) } \\
\text { All outcomes }\end{array}$ & Low risk & $\begin{array}{l}\text { Double-blind } \\
\text { Identical matching placebo }\end{array}$ \\
\hline $\begin{array}{l}\text { Selective reporting (reporting bias) } \\
\text { Other bias }\end{array}$ & Low risk & Full data reported \\
\hline
\end{tabular}

Herfarth 2006

Methods

Participants

Interventions
Randomised, double-blind, double-dummy, multi-centre trial

CD patients were enrolled within 2 weeks of surgery $(\mathrm{N}=79)$

Patients with homozygous TPMT deficiency were excluded

Azathioprine 2 to $2.5 \mathrm{mg} / \mathrm{kg} /$ day for 12 months $(\mathrm{n}=42)$

5 -ASA $4 \mathrm{~g}$ /day for 12 months $(\mathrm{n}=37)$ 


\section{Herfarth 2006 (Continued)}

\begin{tabular}{|c|c|c|}
\hline Outcomes & \multicolumn{2}{|c|}{$\begin{array}{l}\text { Primary outcome: treatment failure end point was } 12 \text { months clinical relapse (not defined) } \\
\text { or endoscopic relapse (not defined) or withdrawal due to any relapse or adverse event. } \\
\text { treatment failure: severe endoscopic relapse, withdrawal due to clinical relapse or adverse } \\
\text { drug reaction }\end{array}$} \\
\hline Notes & \multicolumn{2}{|c|}{$\begin{array}{l}\text { Ended prematurely because an interim analysis revealed that the hypothesis of superiority } \\
\text { of AZA versus 5-ASA could not be tested with the planned sample size }\end{array}$} \\
\hline \multicolumn{3}{|l|}{ Risk of bias } \\
\hline Bias & Authors' judgement & Support for judgement \\
\hline $\begin{array}{l}\text { Random sequence generation (selection } \\
\text { bias) }\end{array}$ & Low risk & Computer-generated randomisation \\
\hline Allocation concealment (selection bias) & Low risk & Centralized randomisation \\
\hline $\begin{array}{l}\text { Blinding of participants and personnel } \\
\text { (performance bias) } \\
\text { All outcomes }\end{array}$ & Low risk & Double-blind, double-dummy \\
\hline $\begin{array}{l}\text { Incomplete outcome data (attrition bias) } \\
\text { All outcomes }\end{array}$ & Low risk & Full data reported \\
\hline Selective reporting (reporting bias) & Low risk & Appropriate data reported \\
\hline Other bias & Low risk & None apparent \\
\hline
\end{tabular}

Reinisch 2010

\begin{tabular}{ll} 
Methods & Randomised, double-blind, double-dummy, multi-centre trial \\
\hline Participants & CD patients within 6 to 24 months of resection with a ileocolonic anastomosis who \\
had no clinical recurrence with CDAI $<200$ but with moderate or severe endoscopic \\
recurrence \\
Exclusion criteria: short bowel syndrome, stricture plasty or an ileocolonic stoma, TPMT \\
deficiency; high serum creatinine; or the use of immunosuppressants or anti-tumour \\
necrosis factor since resection, corticosteroids or oral antibiotics for $>4$ weeks since \\
resection, or NSAIDs within the preceding 2 weeks
\end{tabular}

Interventions

Azathioprine 2 to $2.5 \mathrm{mg} / \mathrm{kg} / \mathrm{day}$ for 12 months $(\mathrm{n}=41)$

Mesalazine $4 \mathrm{~g} /$ day for 12 months $(\mathrm{n}=37)$

Outcomes

Primary outcome: clinical relapse (CDAI $>200$ and an increase of $>60$ points from baseline) at 12 months or withdrawal due to any relapse or adverse event Secondary outcomes: endoscopic improvement (>1 point reduction in Rutgeerts score) or any change in CDAI score, IBDQ score and CRP level from baseline 
Reinisch 2010 (Continued)

\begin{tabular}{|c|c|c|}
\hline Notes & \multicolumn{2}{|c|}{ Included despite endoscopic recurrence as inclusion criteria } \\
\hline \multicolumn{3}{|l|}{ Risk of bias } \\
\hline Bias & Authors' judgement & Support for judgement \\
\hline $\begin{array}{l}\text { Random sequence generation (selection } \\
\text { bias) }\end{array}$ & Low risk & Computer randomisation in blocks of 4 \\
\hline Allocation concealment (selection bias) & Unclear risk & Not described \\
\hline $\begin{array}{l}\text { Blinding of participants and personnel } \\
\text { (performance bias) } \\
\text { All outcomes }\end{array}$ & Low risk & Double-blind \\
\hline $\begin{array}{l}\text { Incomplete outcome data (attrition bias) } \\
\text { All outcomes }\end{array}$ & Low risk & Full data reported \\
\hline Selective reporting (reporting bias) & Low risk & Appropriate data reported \\
\hline Other bias & Low risk & $\begin{array}{l}\text { None apparent although funded by drug } \\
\text { company and some authors employed by } \\
\text { drug company }\end{array}$ \\
\hline
\end{tabular}

Savarino 2013

Methods

Participants

Interventions
Open-label, randomised, controlled trial

Adult patients with ileal or ileocolonic CD undergoing resection $(\mathrm{N}=51)$

Exclusion criteria: more than 10 years of Crohn's disease requiring first resection for short $(10 \mathrm{~cm})$ fibrostenotic stricture, macroscopically active disease not resected during surgery, or the presence of a stoma

Adalimumab 160/80 mg at weeks 0 and 2, followed by $40 \mathrm{mg}$ every 2 weeks for 2 years $(\mathrm{n}=16)$

Azathioprine $2.0 \mathrm{mg} / \mathrm{kg} /$ day for 2 years $(\mathrm{n}=17)$

Mesalamine $3 \mathrm{~g} /$ day for 2 years $(\mathrm{n}=18)$

Outcomes

Primary outcome: the proportion of patients with endoscopic and clinical recurrence at 2 years

Secondary outcomes: quality of life (IBD-Q), adverse events

Notes

Risk of bias

Bias 
Savarino 2013 (Continued)

\begin{tabular}{|c|c|c|}
\hline $\begin{array}{l}\text { Random sequence generation (selection } \\
\text { bias) }\end{array}$ & Low risk & Computer-generated randomisation \\
\hline Allocation concealment (selection bias) & Low risk & $\begin{array}{l}\text { "Patient allocation was concealed and per- } \\
\text { formed by an independent nurse not in- } \\
\text { volved with the trial" }\end{array}$ \\
\hline $\begin{array}{l}\text { Blinding of participants and personnel } \\
\text { (performance bias) } \\
\text { All outcomes }\end{array}$ & High risk & Open-label \\
\hline $\begin{array}{l}\text { Incomplete outcome data (attrition bias) } \\
\text { All outcomes }\end{array}$ & Low risk & $\begin{array}{l}\text { One patient withdrew from the adalimumab } \\
\text { group due to atopic dermatitis } \\
\text { Two patients withdrew from the azathio- } \\
\text { prine group due to a severe exacerbation of } \\
\text { Crohn's disease or an adverse event (severe } \\
\text { abdominal pain and increase of pancreatic } \\
\text { enzymes } \\
\text { Two patients withdrew from the 5-ASA } \\
\text { group due to severe exacerbation of Crohn's } \\
\text { disease }\end{array}$ \\
\hline Selective reporting (reporting bias) & Low risk & Appropriate data reported \\
\hline Other bias & Low risk & None apparent \\
\hline
\end{tabular}

\section{Characteristics of excluded studies [ordered by study ID]}

\begin{tabular}{l|l}
\hline Study & Reason for exclusion \\
\hline Ferrante 2014 & $\begin{array}{l}\text { Abstract publication } \\
\text { All patients received azathioprine } \\
\text { Study compared systematic azathioprine therapy to endoscopically driven azathioprine therapy }\end{array}$ \\
\hline Mañosa 2013 & $\begin{array}{l}\text { All patients received azathioprine } \\
\text { Study compared combination of azathioprine and metronidazole to azathioprine }\end{array}$ \\
\hline Nos 2000 & Not RCT after contacting author \\
\hline
\end{tabular}


DATA ANDANALYSES

Comparison 1. Azathioprine or 6-mercaptopurine versus placebo

\begin{tabular}{|c|c|c|c|c|}
\hline Outcome or subgroup title & $\begin{array}{l}\text { No. of } \\
\text { studies }\end{array}$ & $\begin{array}{c}\text { No. of } \\
\text { participants }\end{array}$ & Statistical method & Effect size \\
\hline 1 Clinical relapse (fixed-effect) & 2 & 168 & Risk Ratio (M-H, Fixed, 95\% CI) & $0.74[0.58,0.94]$ \\
\hline $\begin{array}{l}2 \text { Clinical relapse, sensitivity } \\
\text { analysis, (random-effects) }\end{array}$ & 2 & 168 & Risk Ratio (M-H, Random, 95\% CI) & $0.76[0.61,0.95]$ \\
\hline 3 Endoscopic relapse (fixed-effect) & 1 & & Risk Ratio (M-H, Fixed, 95\% CI) & Totals not selected \\
\hline $\begin{array}{l}4 \text { Adverse events requiring } \\
\text { withdrawal (fixed-effect) }\end{array}$ & 2 & 168 & Risk Ratio (M-H, Fixed, 95\% CI) & $1.33[0.59,2.98]$ \\
\hline
\end{tabular}

Comparison 2. Azathioprine or 6-mercaptopurine versus 5-aminosalicylic acid

\begin{tabular}{|c|c|c|c|c|}
\hline Outcome or subgroup title & $\begin{array}{l}\text { No. of } \\
\text { studies }\end{array}$ & $\begin{array}{c}\text { No. of } \\
\text { participants }\end{array}$ & Statistical method & Effect size \\
\hline 1 Clinical relapse (fixed-effect) & 5 & 425 & Risk Ratio (M-H, Fixed, 95\% CI) & $1.15[0.99,1.34]$ \\
\hline $\begin{array}{l}2 \text { Clinical relapse,sensitivity } \\
\text { analysis (random-effects) }\end{array}$ & 5 & 425 & Risk Ratio (M-H, Random, 95\% CI) & $1.14[0.93,1.41]$ \\
\hline $\begin{array}{l}3 \text { Clinical relapse, sensitivity } \\
\text { analysis excluding study } \\
\text { that enrolled patients with } \\
\text { endoscopic recurrence, } \\
\text { (fixed-effect) }\end{array}$ & 4 & 347 & Risk Ratio (M-H, Fixed, 95\% CI) & $1.06[0.91,1.24]$ \\
\hline $\begin{array}{l}4 \text { Clinical relapse, subgroup } \\
\text { analysis by drug type } \\
\text { (fixed-effect) }\end{array}$ & 5 & 425 & Risk Ratio (M-H, Fixed, 95\% CI) & $1.15[0.99,1.34]$ \\
\hline 4.1 Azathioprine & 4 & 334 & Risk Ratio (M-H, Fixed, 95\% CI) & $1.25[1.04,1.51]$ \\
\hline 4.2 6-mercaptopurine & 1 & 91 & Risk Ratio (M-H, Fixed, 95\% CI) & $0.91[0.70,1.18]$ \\
\hline $\begin{array}{l}5 \text { Clinical relapse, subgroup } \\
\text { analysis by length of follow-up }\end{array}$ & 5 & 425 & Risk Ratio (M-H, Fixed, 95\% CI) & $1.15[0.99,1.34]$ \\
\hline 5.112 months & 2 & 157 & Risk Ratio (M-H, Fixed, 95\% CI) & $1.40[1.12,1.74]$ \\
\hline 5.224 months & 3 & 268 & Risk Ratio (M-H, Fixed, 95\% CI) & $1.01[0.81,1.24]$ \\
\hline 6 Endoscopic relapse (fixed-effect) & 2 & & Risk Ratio (M-H, Fixed, 95\% CI) & Totals not selected \\
\hline 7 Adverse events (fixed-effect) & 4 & 334 & Risk Ratio (M-H, Fixed, 95\% CI) & $1.08[0.93,1.27]$ \\
\hline $\begin{array}{l}8 \text { Adverse events requiring } \\
\text { withdrawal (fixed-effect) }\end{array}$ & 5 & 423 & Risk Ratio (M-H, Fixed, 95\% CI) & $2.07[1.26,3.39]$ \\
\hline $\begin{array}{l}9 \text { Adverse events requiring } \\
\text { withdrawal, subgroup analysis } \\
\text { by drug type (fixed-effect) }\end{array}$ & 5 & 423 & Risk Ratio (M-H, Fixed, 95\% CI) & $2.07[1.26,3.39]$ \\
\hline 9.1 Azathioprine & 4 & 332 & Risk Ratio (M-H, Fixed, 95\% CI) & $2.35[1.31,4.22]$ \\
\hline 9.2 6-mercaptopurine & 1 & 91 & Risk Ratio (M-H, Fixed, 95\% CI) & $1.40[0.54,3.62]$ \\
\hline
\end{tabular}




\section{Comparison 3. Azathioprine versus infliximab}

Outcome or subgroup title

1 Clinical relapse

2 Endoscopic relapse

3 Adverse events requiring withdrawal

$\begin{array}{cc}\text { No. of } & \text { No. of } \\ \text { studies } & \text { participants }\end{array}$

1

1

1

$\begin{array}{ll}1 & \text { Risk Ratio (M-H, Fixed, 95\% CI) } \\ 1 & \text { Risk Ratio (M-H, Fixed, 95\% CI) } \\ 1 & \text { Risk Ratio (M-H, Fixed, 95\% CI) }\end{array}$

Risk Ratio (M-H, Fixed, 95\% CI)

\section{Effect size}

Totals not selected

Totals not selected

Totals not selected

Comparison 4. Azathioprine versus adalimumab

\begin{tabular}{|c|c|c|c|c|}
\hline Outcome or subgroup title & $\begin{array}{l}\text { No. of } \\
\text { studies }\end{array}$ & $\begin{array}{c}\text { No. of } \\
\text { participants }\end{array}$ & Statistical method & Effect size \\
\hline 1 Clinical relapse & 1 & & Risk Ratio (M-H, Fixed, 95\% CI) & Totals not selected \\
\hline 2 Endoscopic relapse & 1 & & Risk Ratio (M-H, Fixed, 95\% CI) & Totals not selected \\
\hline 3 Adverse events & 1 & & Risk Ratio (M-H, Fixed, 95\% CI) & Totals not selected \\
\hline $\begin{array}{l}4 \text { Adverse events requiring } \\
\text { withdrawal }\end{array}$ & 1 & & Risk Ratio (M-H, Fixed, 95\% CI) & Totals not selected \\
\hline
\end{tabular}

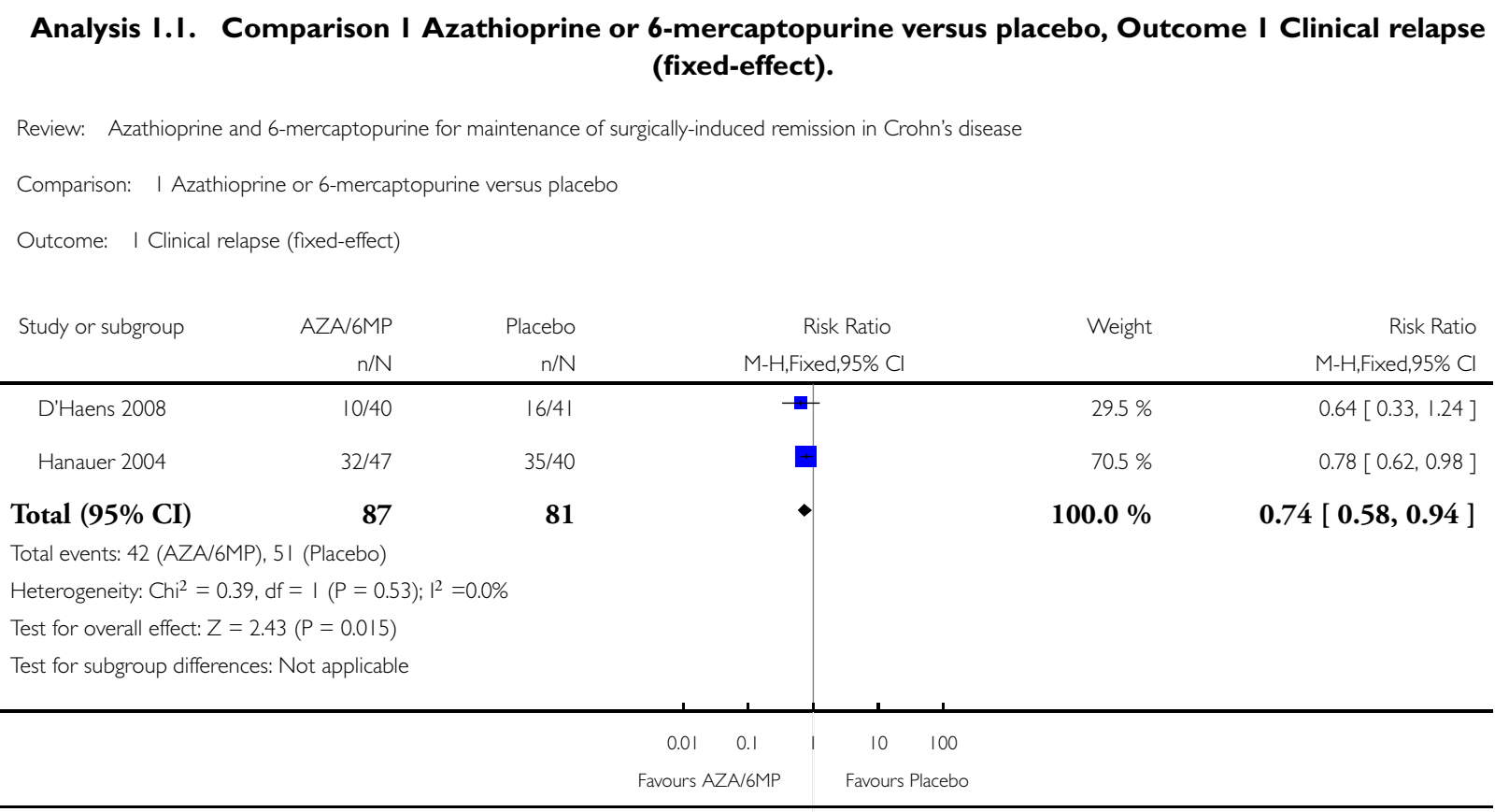


Analysis I.2. Comparison I Azathioprine or 6-mercaptopurine versus placebo, Outcome 2 Clinical relapse, sensitivity analysis, (random-effects).

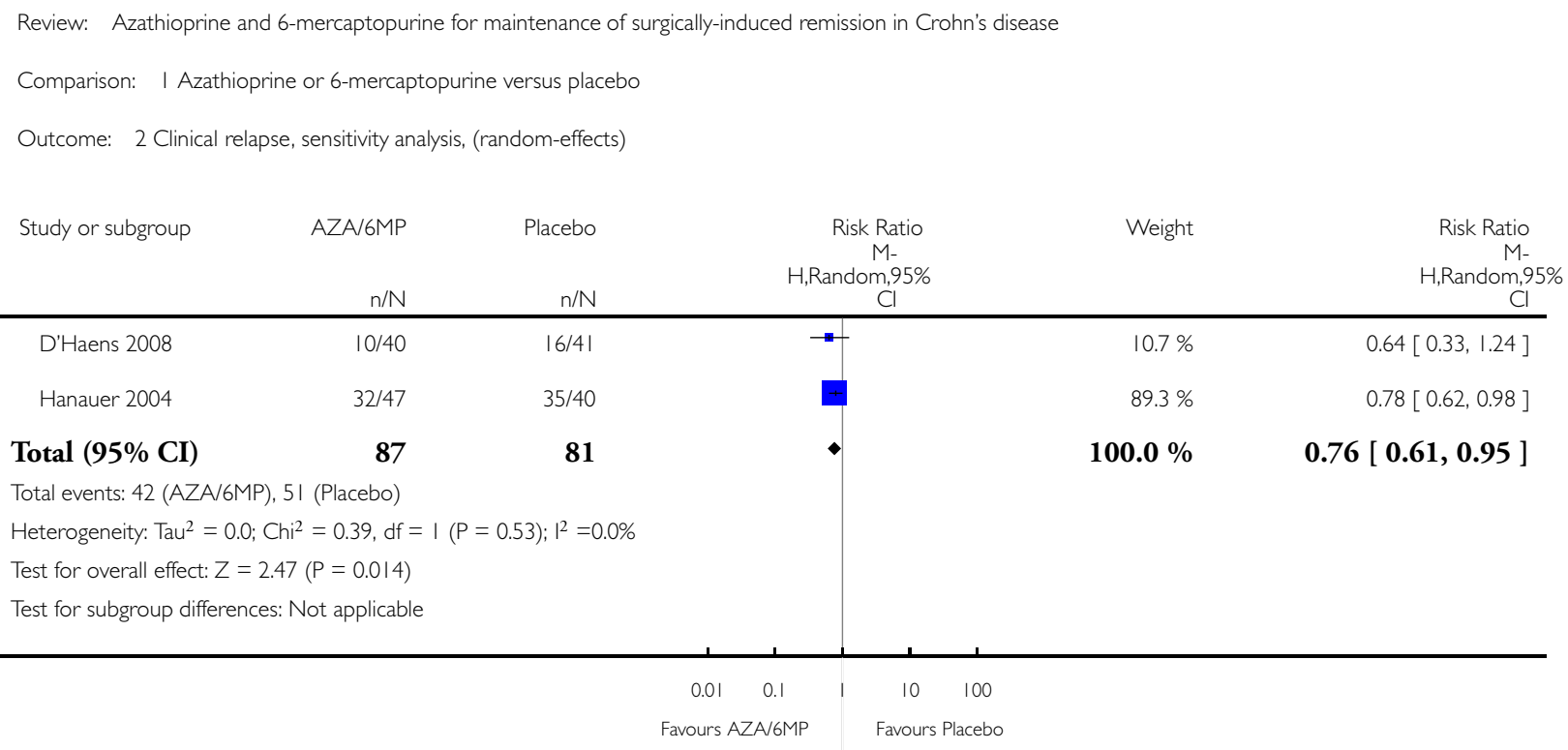


Analysis I.3. Comparison I Azathioprine or 6-mercaptopurine versus placebo, Outcome 3 Endoscopic relapse (fixed-effect).

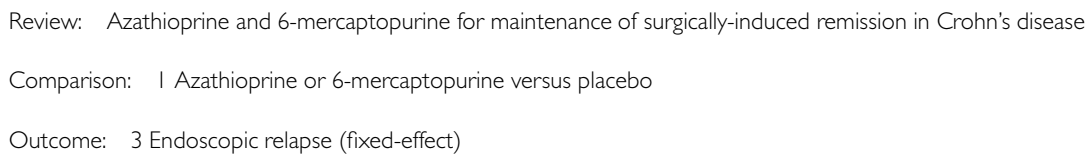

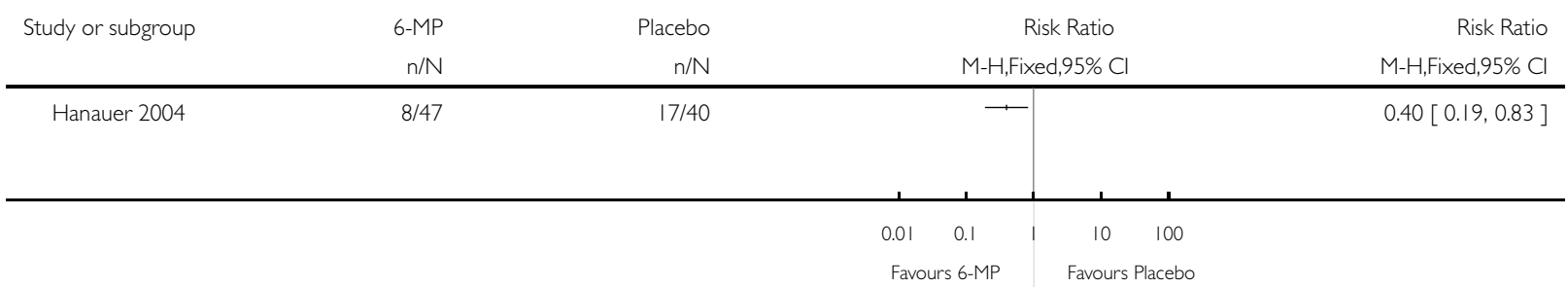

Analysis I.4. Comparison I Azathioprine or 6-mercaptopurine versus placebo, Outcome 4 Adverse events requiring withdrawal (fixed-effect).

Review: Azathioprine and 6-mercaptopurine for maintenance of surgically-induced remission in Crohn's disease

Comparison: I Azathioprine or 6-mercaptopurine versus placebo

Outcome: 4 Adverse events requiring withdrawal (fixed-effect)

\begin{tabular}{|c|c|c|c|c|c|}
\hline \multirow[t]{2}{*}{ Study or subgroup } & $\mathrm{AZA} / 6 \mathrm{MP}$ & Placebo & Risk Ratio & Weight & Risk Ratio \\
\hline & $\mathrm{n} / \mathrm{N}$ & $\mathrm{n} / \mathrm{N}$ & M-H,Fixed,95\% Cl & & M-H,Fixed,95\% Cl \\
\hline D'Haens 2008 & $4 / 40$ & $5 / 41$ & 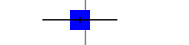 & $53.3 \%$ & $0.82[0.24,2.84]$ \\
\hline Hanauer 2004 & $9 / 47$ & $4 / 40$ & & $46.7 \%$ & $1.91[0.64,5.75]$ \\
\hline
\end{tabular}

Total (95\% CI)

87

81

$100.0 \%$

$1.33[0.59,2.98]$

Total events: 13 (AZA/6MP), 9 (Placebo)

Heterogeneity: $\mathrm{Chi}^{2}=1.01, \mathrm{df}=1(\mathrm{P}=0.32) ; \mathrm{I}^{2}=1 \%$

Test for overall effect: $Z=0.70(P=0.49)$

Test for subgroup differences: Not applicable

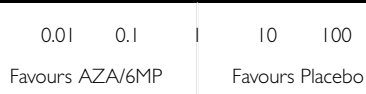


Analysis 2.1. Comparison 2 Azathioprine or 6-mercaptopurine versus 5-aminosalicylic acid, Outcome I Clinical relapse (fixed-effect).

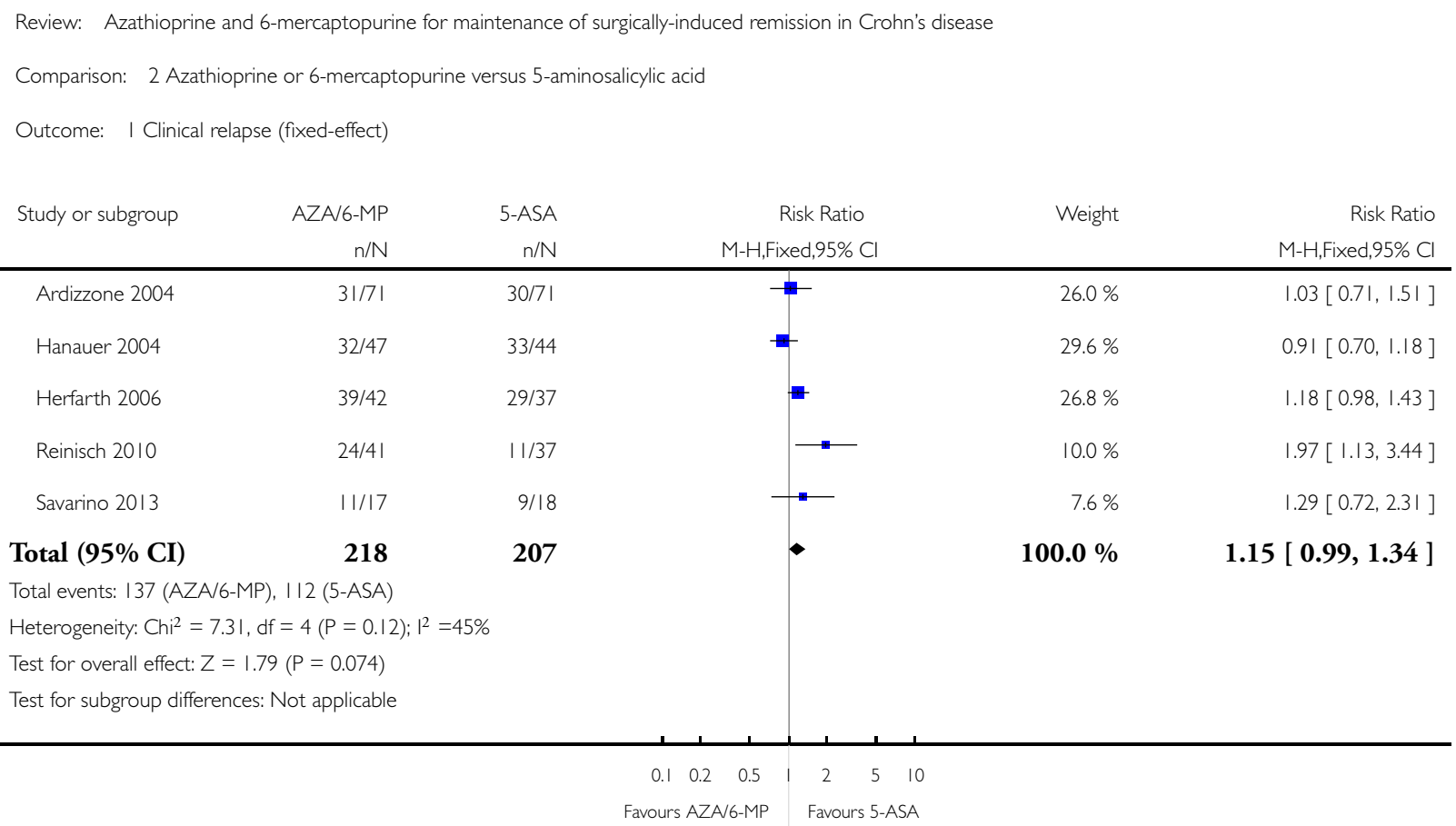


Analysis 2.2. Comparison 2 Azathioprine or 6-mercaptopurine versus 5-aminosalicylic acid, Outcome 2 Clinical relapse,sensitivity analysis (random-effects).

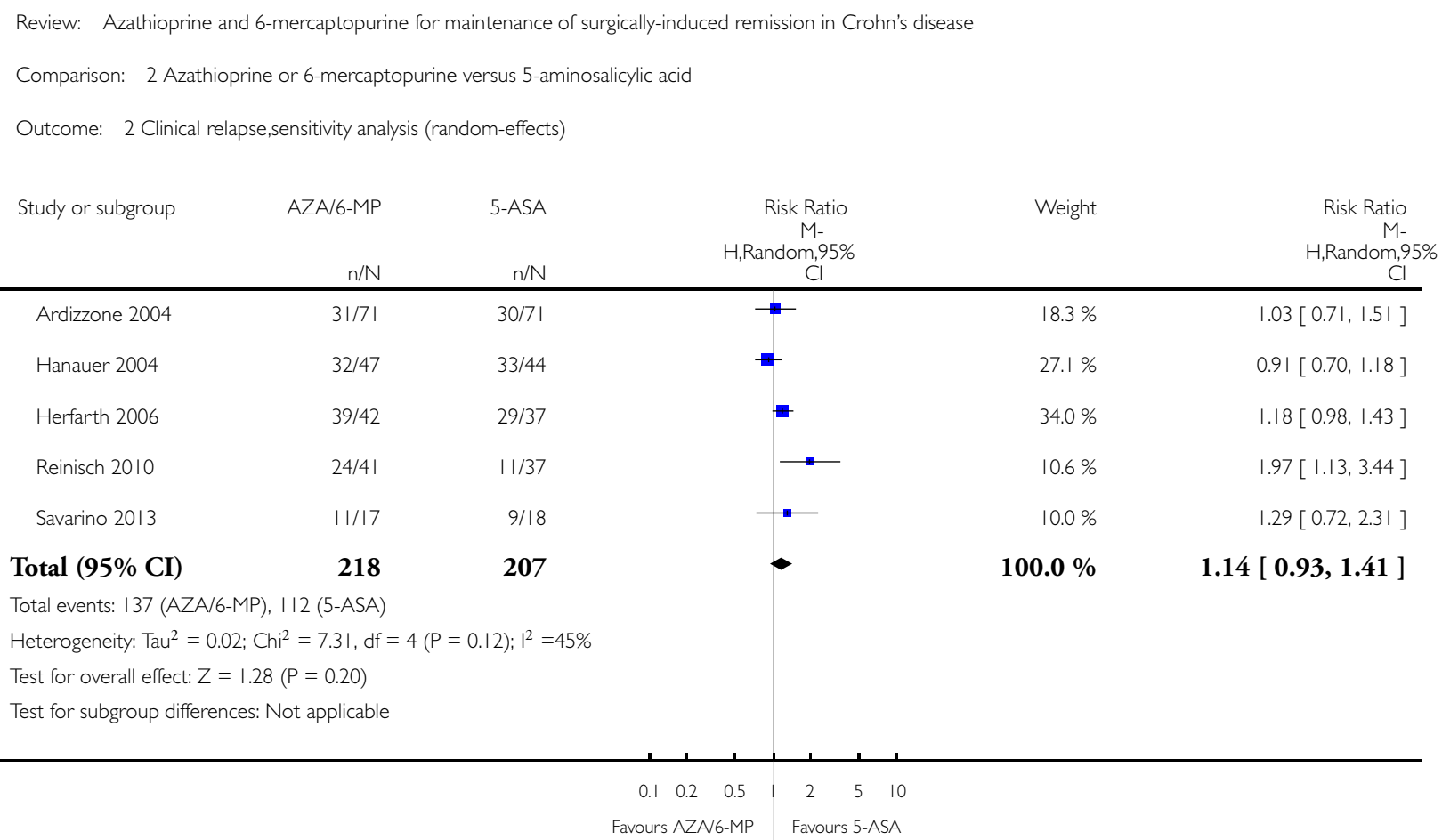


Analysis 2.3. Comparison 2 Azathioprine or 6-mercaptopurine versus 5-aminosalicylic acid, Outcome 3 Clinical relapse, sensitivity analysis excluding study that enrolled patients with endoscopic recurrence, (fixedeffect).

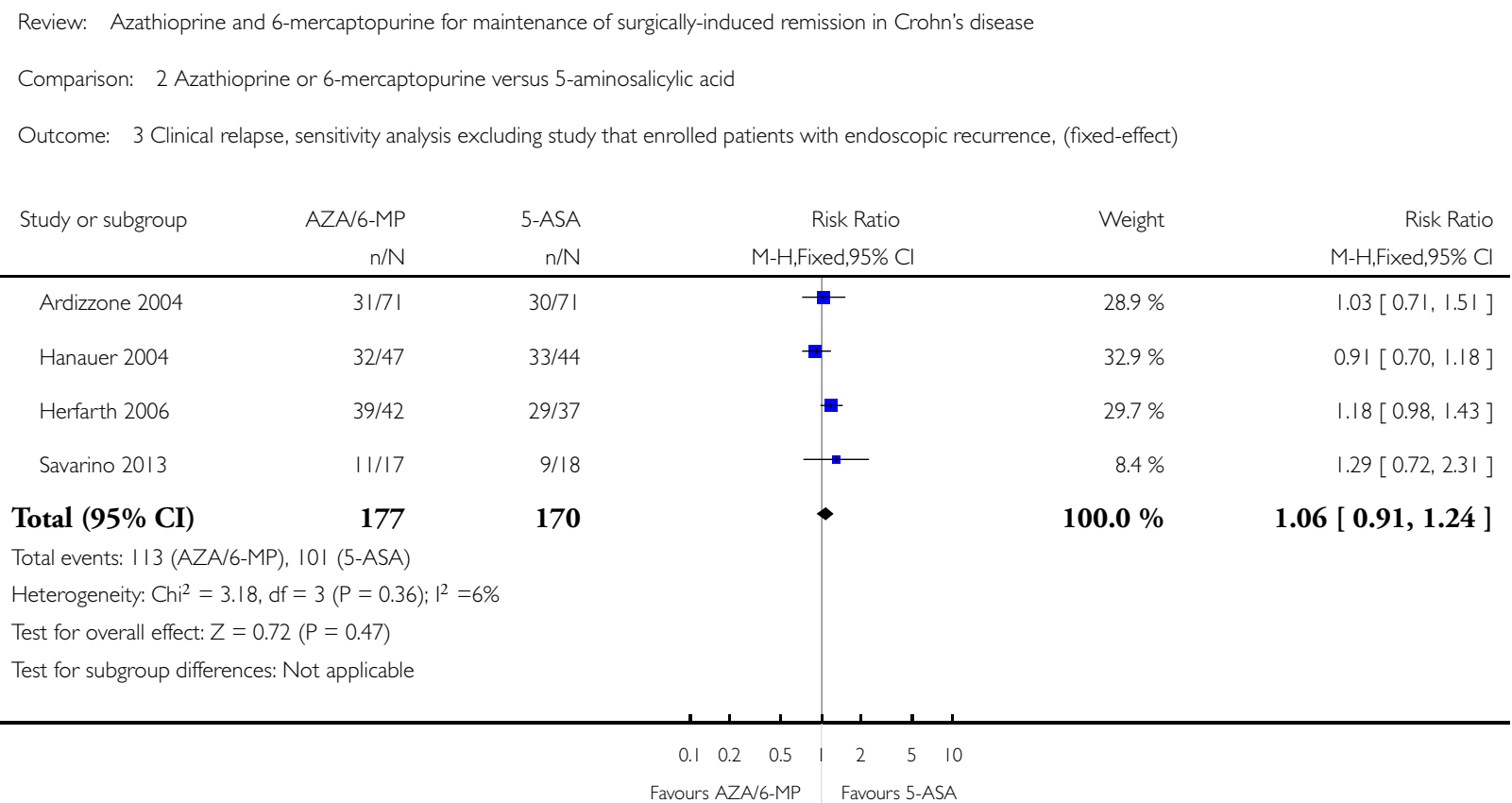


Analysis 2.4. Comparison 2 Azathioprine or 6-mercaptopurine versus 5-aminosalicylic acid, Outcome 4 Clinical relapse, subgroup analysis by drug type (fixed-effect).

Review: Azathioprine and 6-mercaptopurine for maintenance of surgically-induced remission in Crohn's disease

Comparison: 2 Azathioprine or 6-mercaptopurine versus 5-aminosalicylic acid

Outcome: 4 Clinical relapse, subgroup analysis by drug type (fixed-effect)

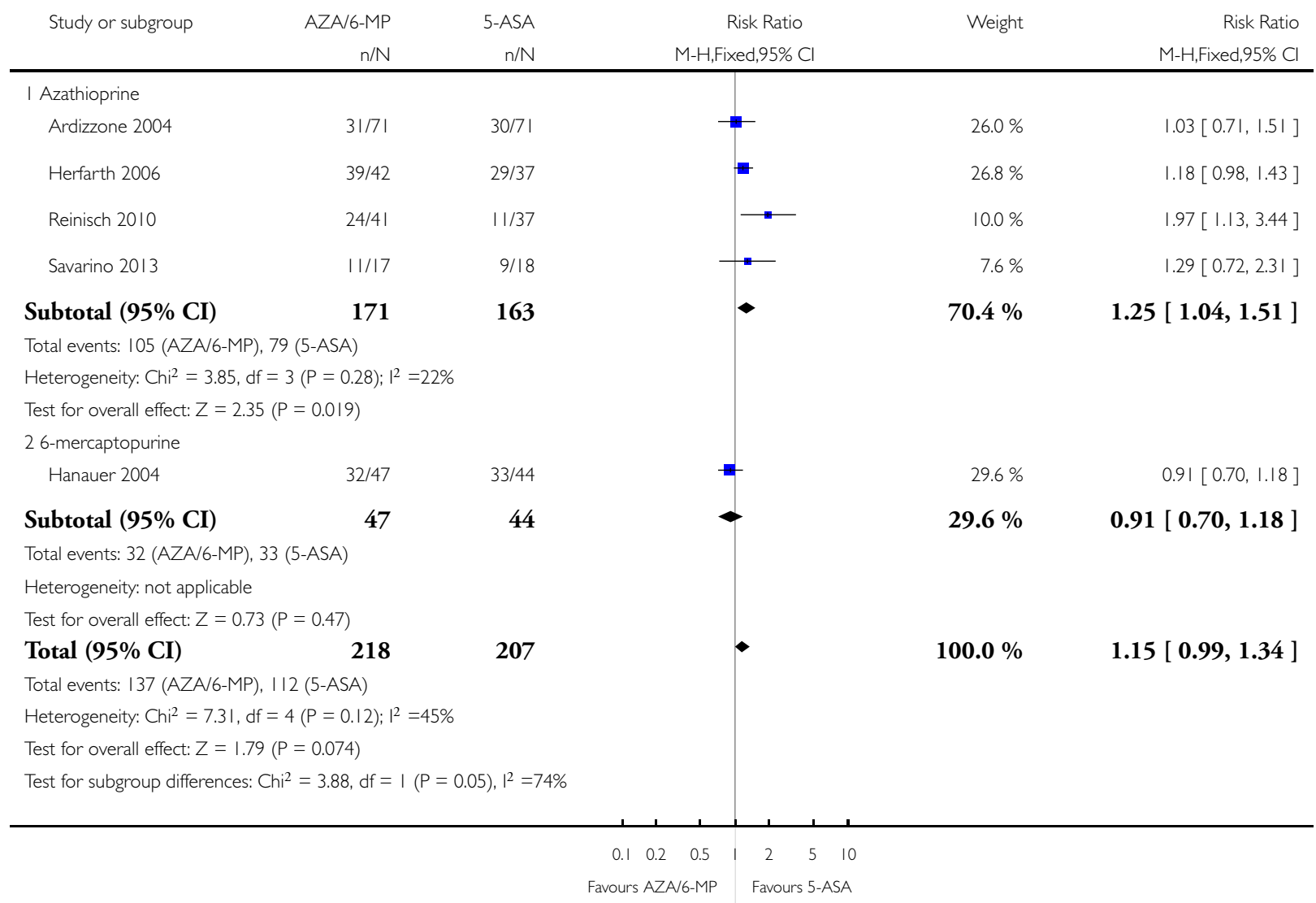


Analysis 2.5. Comparison 2 Azathioprine or 6-mercaptopurine versus 5-aminosalicylic acid, Outcome 5 Clinical relapse, subgroup analysis by length of follow-up.

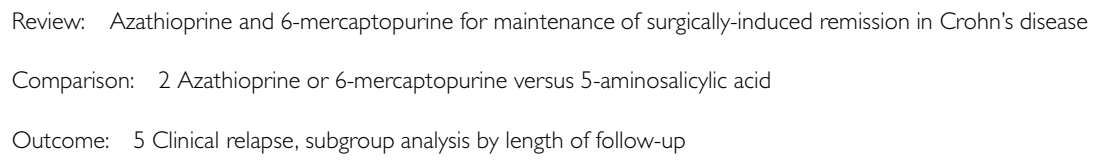

Subtotal (95\% CI)

Total events: 63 (AZA/6-MP), 40 (5-ASA)

Heterogeneity: $\mathrm{Ch}^{2}=4.4 \mathrm{I}, \mathrm{df}=\mathrm{I}(\mathrm{P}=0.04) ; \mathrm{I}^{2}=77 \%$

Test for overall effect: $Z=2.98(P=0.0029)$

224 months

Ardizzone 2004

Hanauer 2004

Savarino 2013

$$
11 / 17
$$

Subtotal (95\% CI)

135

Total events: 74 (AZA/6-MP), 72 (5-ASA)

Heterogeneity: Chi $^{2}=1.34, d f=2(P=0.5 \mathrm{I}) ;\left.\right|^{2}=0.0 \%$

Test for overall effect: $Z=0.05(P=0.96)$

Total (95\% CI)

Total events: 137 (AZA/6-MP), I 12 (5-ASA)

Heterogeneity: $\mathrm{Chi}^{2}=7.31, \mathrm{df}=4(P=0.12) ; \mathrm{I}^{2}=45 \%$

Test for overall effect: $Z=1.79(P=0.074)$

Test for subgroup differences: $\mathrm{Chi}^{2}=4.48, \mathrm{df}=\mathrm{I}(\mathrm{P}=0.03), \mathrm{I}^{2}=78 \%$

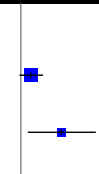

$26.8 \%$

$10.0 \%$

$1.18[0.98,1.43]$

$1.97[1.13,3.44]$

$36.8 \%$

$1.40[1.12,1.74]$
133

$26.0 \%$

$29.6 \%$

$7.6 \%$

$63.2 \%$

207

$1.15[0.99,1.34]$ 
Analysis 2.6. Comparison 2 Azathioprine or 6-mercaptopurine versus 5-aminosalicylic acid, Outcome 6 Endoscopic relapse (fixed-effect).

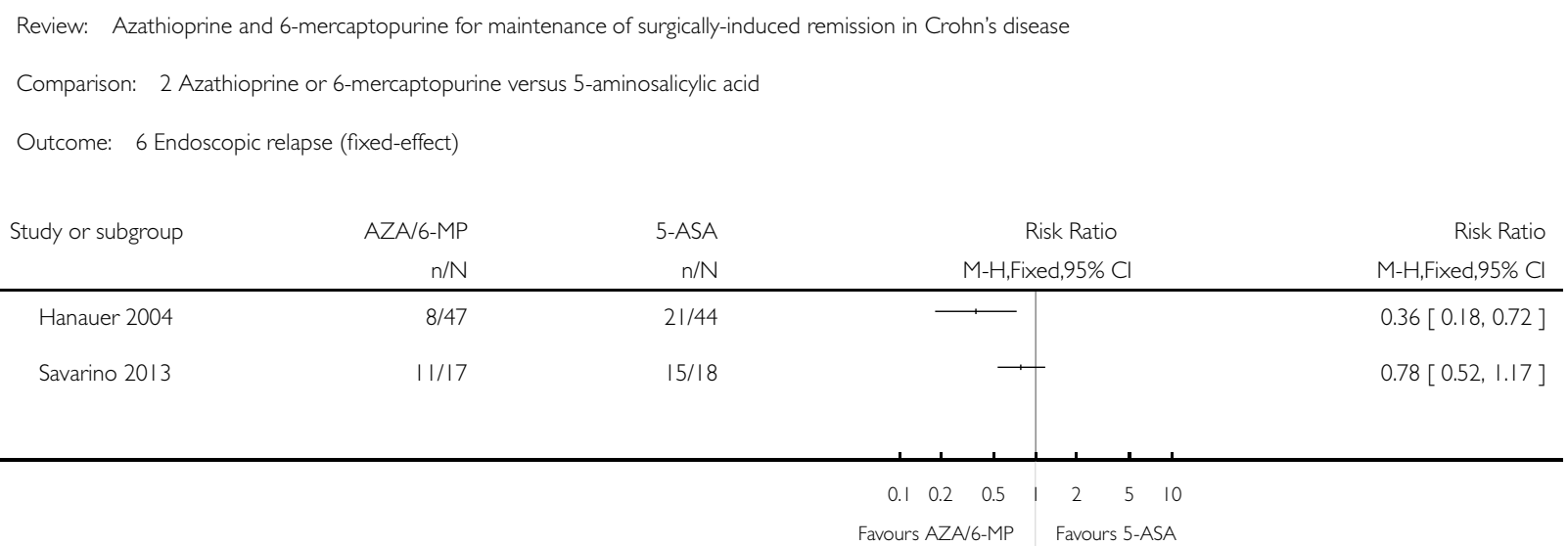

\section{Analysis 2.7. Comparison 2 Azathioprine or 6-mercaptopurine versus 5-aminosalicylic acid, Outcome 7} Adverse events (fixed-effect).

Review: Azathioprine and 6-mercaptopurine for maintenance of surgically-induced remission in Crohn's disease

Comparison: 2 Azathioprine or 6-mercaptopurine versus 5-aminosalicylic acid

Outcome: 7 Adverse events (fixed-effect)

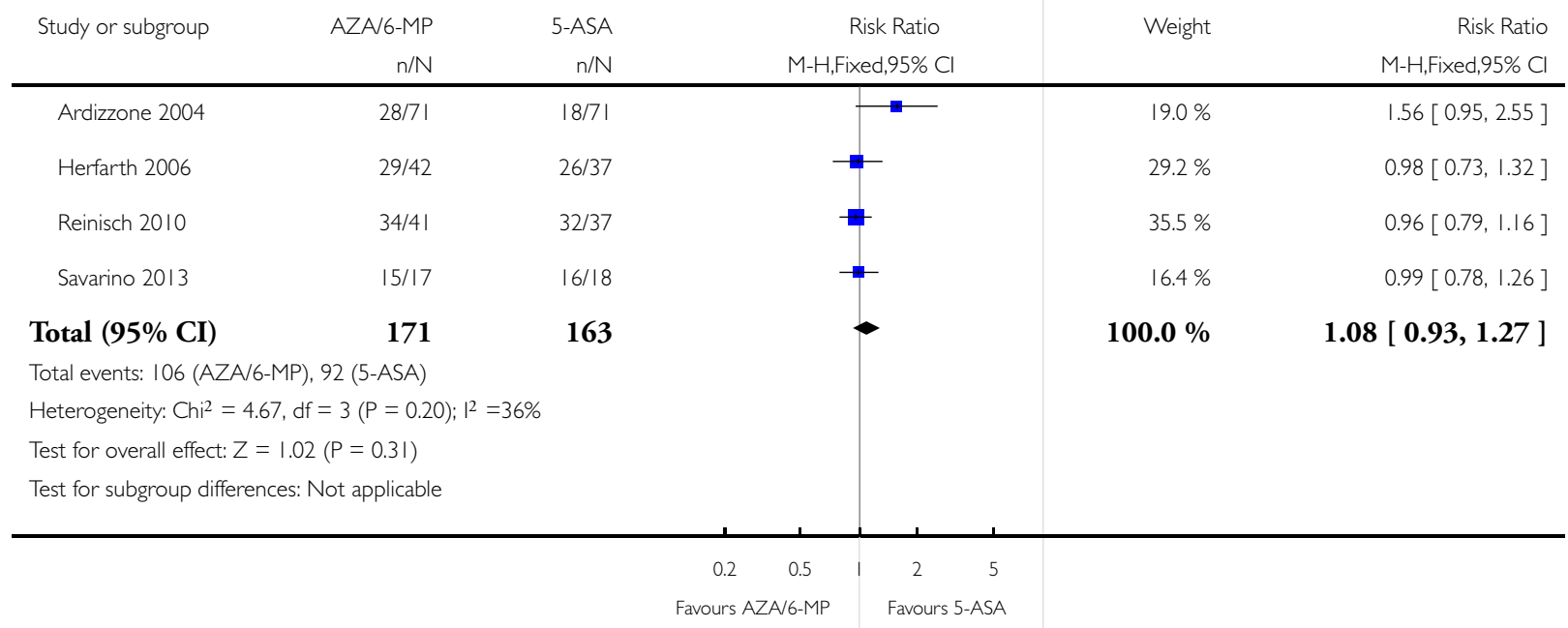


Analysis 2.8. Comparison 2 Azathioprine or 6-mercaptopurine versus 5-aminosalicylic acid, Outcome 8 Adverse events requiring withdrawal (fixed-effect).

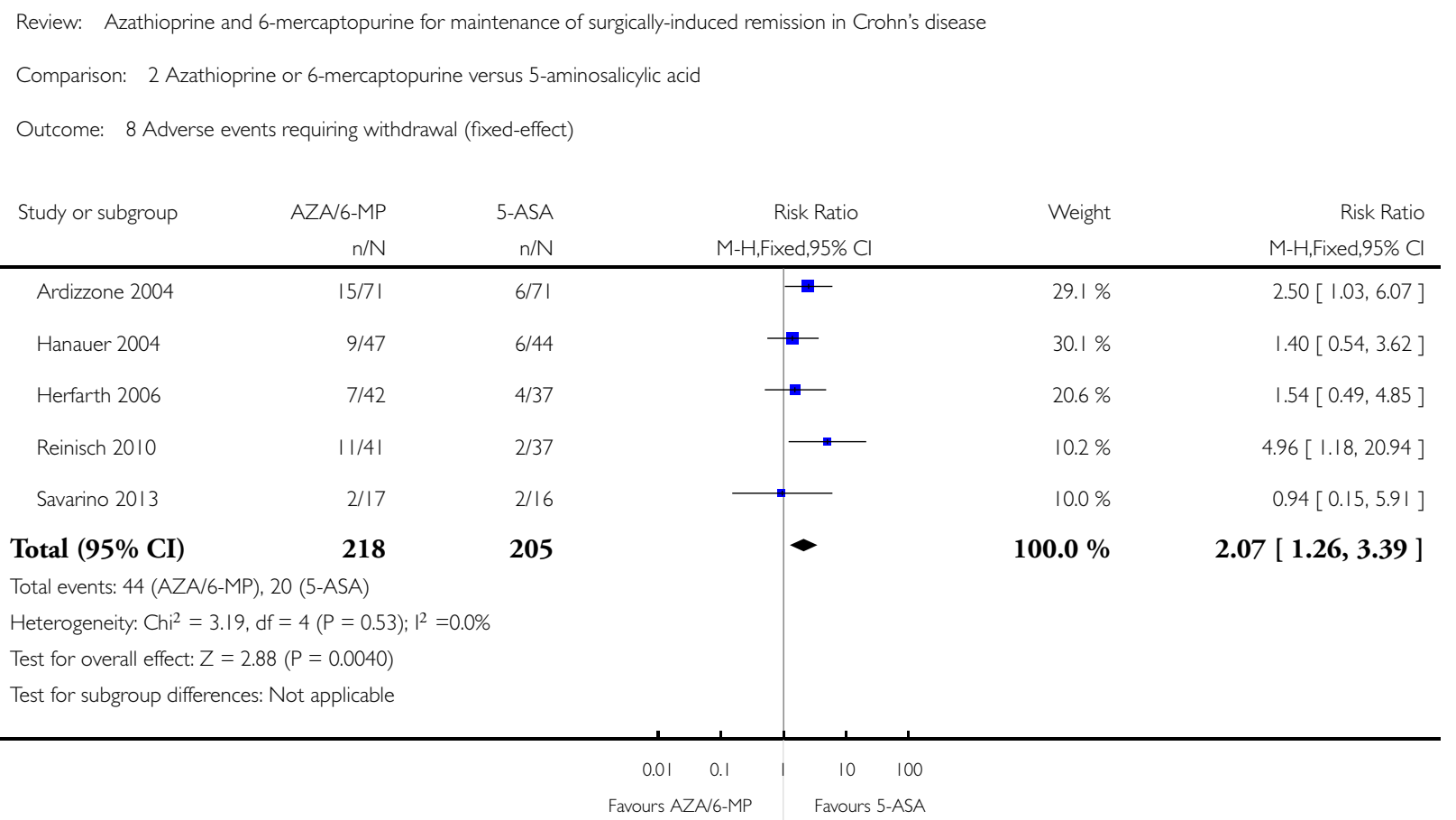


Analysis 2.9. Comparison 2 Azathioprine or 6-mercaptopurine versus 5-aminosalicylic acid, Outcome 9 Adverse events requiring withdrawal, subgroup analysis by drug type (fixed-effect).

Review: Azathioprine and 6-mercaptopurine for maintenance of surgically-induced remission in Crohn's disease

Comparison: 2 Azathioprine or 6-mercaptopurine versus 5-aminosalicylic acid

Outcome: 9 Adverse events requiring withdrawal, subgroup analysis by drug type (fixed-effect)

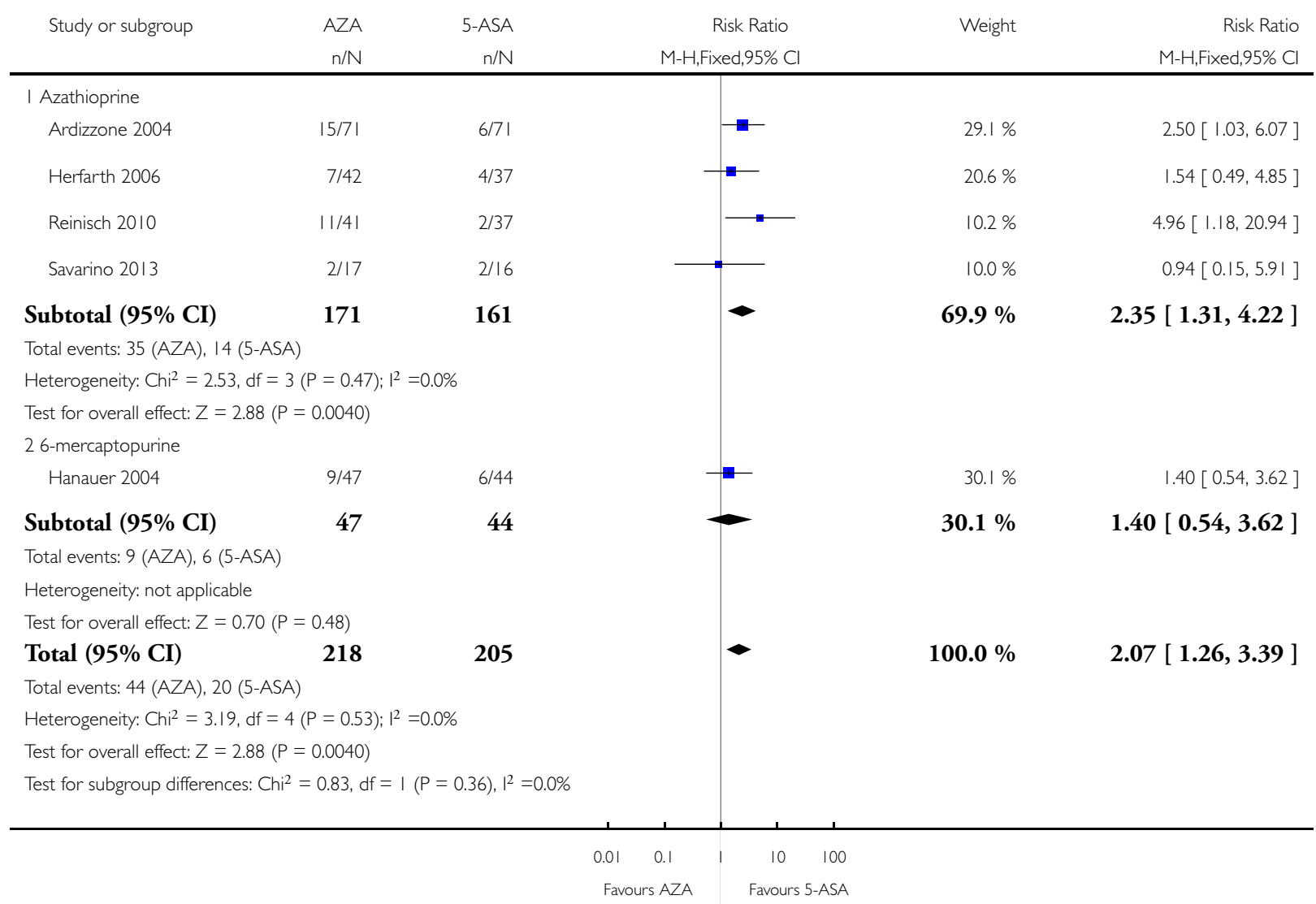


Analysis 2.10. Comparison 2 Azathioprine or 6-mercaptopurine versus 5-aminosalicylic acid, Outcome 10 Serious adverse events (random-effects).

Review: Azathioprine and 6-mercaptopurine for maintenance of surgically-induced remission in Crohn's disease

Comparison: 2 Azathioprine or 6-mercaptopurine versus 5-aminosalicylic acid

Outcome: 10 Serious adverse events (random-effects)

\begin{tabular}{|c|c|c|c|c|c|}
\hline Study or subgroup & AZA/6-MP & n/N & $\begin{array}{c}\text { Risk Ratio } \\
\text { M- } \\
\text { H,Random,95\% } \\
\text { Cl }\end{array}$ & Weight & $\begin{array}{c}\text { Risk Ratio } \\
\text { M- } \\
\text { H,Random,95\% } \\
\mathrm{Cl}\end{array}$ \\
\hline Hanauer 2004 & $0 / 47$ & $1 / 44$ & 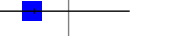 & $48.4 \%$ & $0.31[0.01,7.47]$ \\
\hline Reinisch 2010 & $|0 / 4|$ & $0 / 37$ & 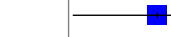 & $51.6 \%$ & $19.00[1.15,313.35]$ \\
\hline
\end{tabular}

Total (95\% CI)

88

81

$100.0 \%$

$2.61[0.04,162.02]$

Total events: 10 (AZA/6-MP), I (5-ASA)

Heterogeneity: $\mathrm{Tau}^{2}=6.56 ; \mathrm{Chi}^{2}=3.81, \mathrm{df}=\mathrm{I}(\mathrm{P}=0.05) ; \mathrm{I}^{2}=74 \%$

Test for overall effect: $Z=0.45(P=0.65)$

Test for subgroup differences: Not applicable

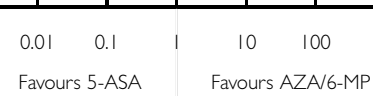

Analysis 3.I. Comparison 3 Azathioprine versus infliximab, Outcome I Clinical relapse.

Review: Azathioprine and 6-mercaptopurine for maintenance of surgically-induced remission in Crohn's disease

Comparison: 3 Azathioprine versus infliximab

Outcome: I Clinical relapse

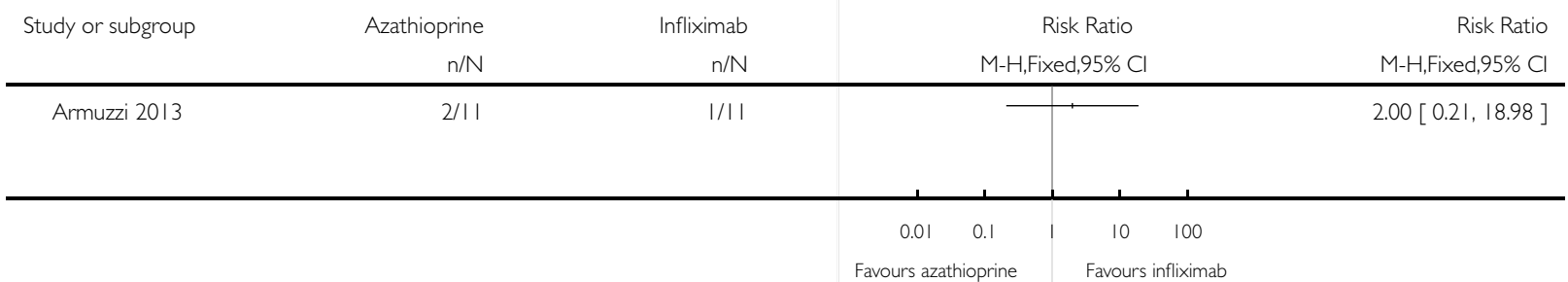




\section{Analysis 3.2. Comparison 3 Azathioprine versus infliximab, Outcome 2 Endoscopic relapse.}

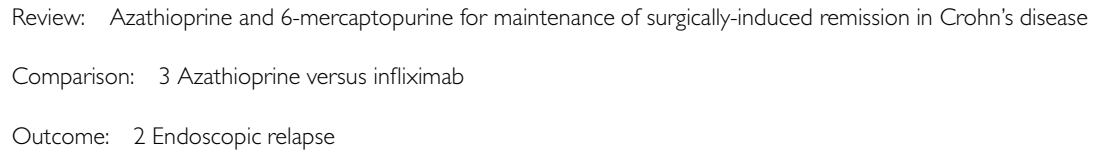

\begin{tabular}{llll|l} 
& $\mathrm{n} / \mathrm{N}$ & $\mathrm{M} / \mathrm{N}$ & $\mathrm{M}-\mathrm{H}, \mathrm{Fixed}, 95 \% \mathrm{Cl}$ & $1, \mathrm{Fixed}, 95 \% \mathrm{Cl}$ \\
\hline Armuzzi 2013 & $4 / 10$ & $\mathrm{I} / \mathrm{II}$ & $4.40[0.59,33.07]$ \\
\hline
\end{tabular}

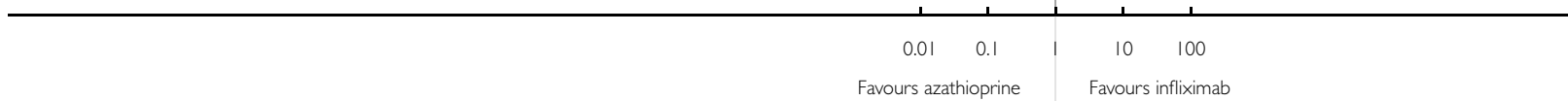

Analysis 3.3. Comparison 3 Azathioprine versus infliximab, Outcome 3 Adverse events requiring withdrawal.

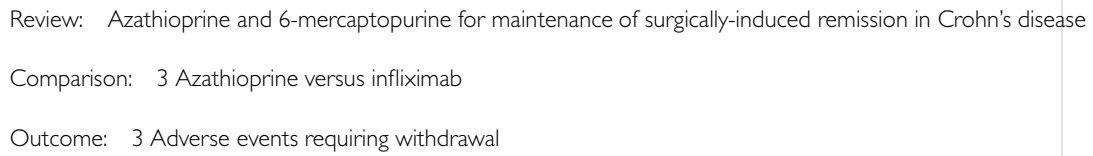

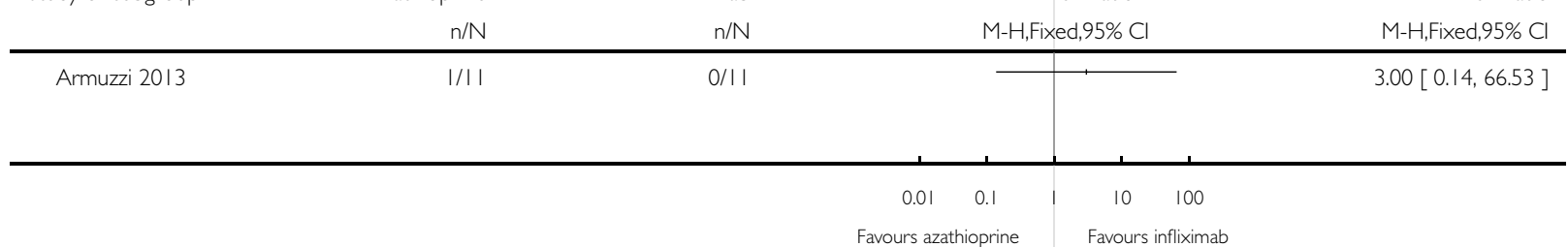




\section{Analysis 4.I. Comparison 4 Azathioprine versus adalimumab, Outcome I Clinical relapse.}

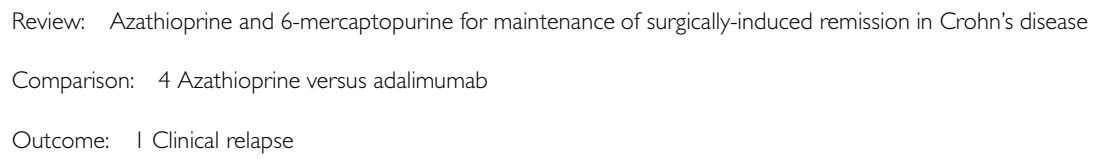

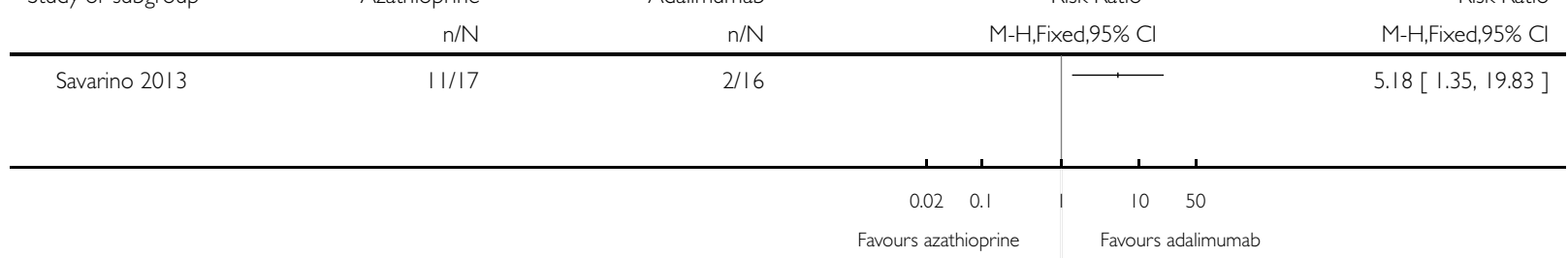

Analysis 4.2. Comparison 4 Azathioprine versus adalimumab, Outcome 2 Endoscopic relapse.

Review: Azathioprine and 6-mercaptopurine for maintenance of surgically-induced remission in Crohn's disease

Comparison: 4 Azathioprine versus adalimumab

Outcome: 2 Endoscopic relapse

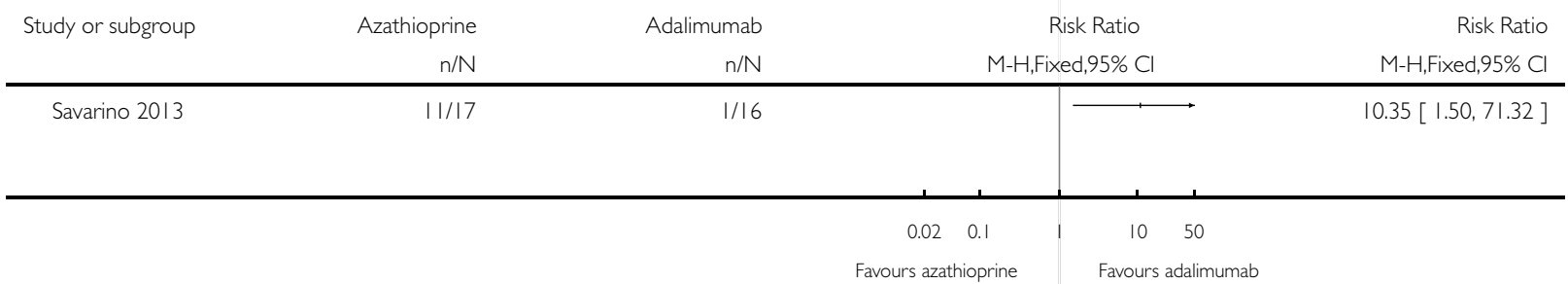




\section{Analysis 4.3. Comparison 4 Azathioprine versus adalimumab, Outcome 3 Adverse events.}

Review: Azathioprine and 6-mercaptopurine for maintenance of surgically-induced remission in Crohn's disease

Comparison: 4 Azathioprine versus adalimumab

Outcome: 3 Adverse events

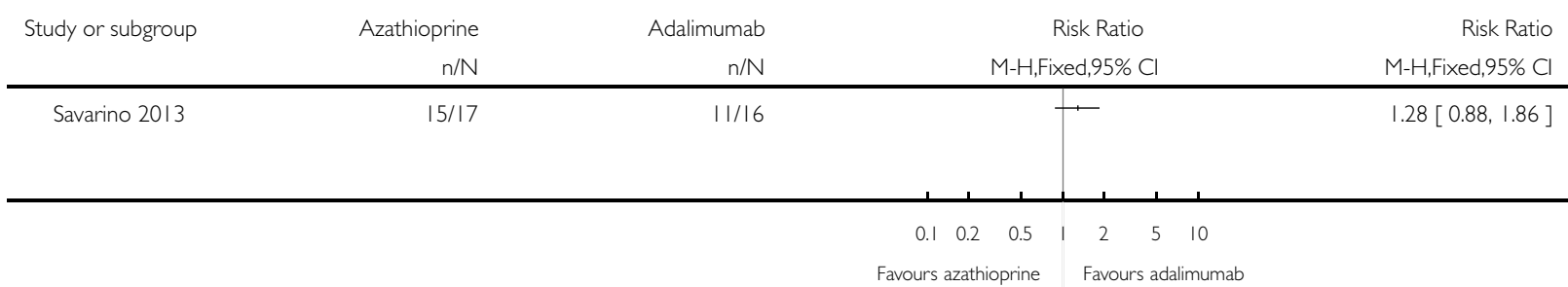

Analysis 4.4. Comparison 4 Azathioprine versus adalimumab, Outcome 4 Adverse events requiring withdrawal.

Review: Azathioprine and 6-mercaptopurine for maintenance of surgically-induced remission in Crohn's disease

Comparison: 4 Azathioprine versus adalimumab

Outcome: 4 Adverse events requiring withdrawal

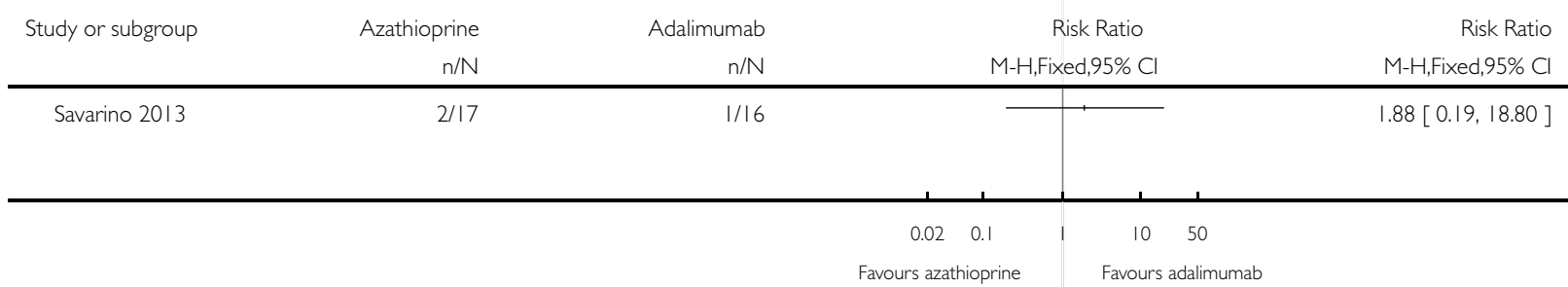




\section{A P P E N D I C ES}

\section{Appendix I. Search Strategies}

\section{PubMed}

\#1 crohn* OR IBD OR “inflammatory bowel disease" OR regional enteritis OR ileitis

\# 2 singl* OR doubl* OR tripl* OR trebl* OR blind* OR mask* OR placebo* OR single-blind* OR double-blind* OR triple-blind* OR random* OR (controlled clinical)

\# 3 \#1 AND \# 2

\# 4 AZA or azathioprine

\# 5 6-mercaptopurine or mercaptopurine or 6-MP or 6MP

\# 6 anti-metabolite* or antimetabolite*

\# 7 \#4 OR \#5 OR \#6

\# 8 \#3 AND \#7

\# 9 surgery or surgic* ${ }^{*}$ or post-surgical or post-surgery or postoperative or post-operative or resection or operation

\# 10 \#8 AND \#9

\section{MEDLINE}

1 random $\$$.tw.

2 factorial $\$$.tw.

3 (crossover\$ or cross over\$ or cross-over\$).tw.

4 placebo\$.tw.

5 single blind.mp.

6 double blind.mp.

7 triple blind.mp.

8 (singl\$ adj blind\$).tw.

9 (double $\$$ adj blind\$).tw.

10 (tripl\$ adj blind\$).tw.

11 assign $\$ . t w$.

12 allocat\$.tw.

13 crossover procedure/

14 double blind procedure/

15 single blind procedure/

16 triple blind procedure/

17 randomized controlled trial/

18 or/1-17

19. exp Crohn disease/ or crohn*.mp.

20. inflammatory bowel disease.mp.

21. IBD.mp.

22. 19 or 20 or 21

23. 18 and 22

24. azathioprine.mp. or exp azathioprine derivative/ or exp azathioprine/

25. 6-mercaptopurine.mp. or exp mercaptopurine/

26. (AZA or 6-MP or 6MP).mp.

27. exp antimetabolite/ or anti-metabolite*.mp.

28. antimetabolite*.mp.

29. 24 or 25 or 26 or 27 or 28

30. 23 and 29

31. surgery.mp. or surgery/

32. (surgical or surgically).mp.

33. surgic*.mp.

34. (post-surgical or post-surgery).mp.

35. (postoperative or post-operative).mp.

36. resection.mp. or surgery/ 
37. operation.mp. or surgery/

38.31 or 32 or 33 or 34 or 35 or 36 or 37

39.30 and 38

\section{EMBASE}

1 random\$.tw.

2 factorial\$.tw.

3 (crossover\$ or cross over\$ or cross-over\$).tw.

4 placebo\$.tw.

5 single blind.mp.

6 double blind.mp.

7 triple blind.mp.

8 (singl\$ adj blind\$).tw.

9 (double\$ adj blind\$).tw.

10 (tripl\$ adj blind\$).tw.

11 assign \$.tw.

12 allocat\$.tw.

13 crossover procedure/

14 double blind procedure/

15 single blind procedure/

16 triple blind procedure/

17 randomized controlled trial/

18 or/1-17

19. exp Crohn disease/ or crohn*.mp.

20. inflammatory bowel disease.mp.

21. IBD.mp.

22. 19 or 20 or 21

23. 18 and 22

24. azathioprine.mp. or exp azathioprine derivative/ or exp azathioprine/

25. 6-mercaptopurine.mp. or exp mercaptopurine/

26. (AZA or 6-MP or 6MP).mp.

27. exp antimetabolite/ or anti-metabolite*.mp.

28. antimetabolite*.mp.

29.24 or 25 or 26 or 27 or 28

30. 23 and 29

31. surgery.mp. or surgery/

32. (surgical or surgically).mp.

33. surgic*.mp.

34. (post-surgical or post-surgery).mp.

35. (postoperative or post-operative).mp.

36. resection.mp. or surgery/

37. operation.mp. or surgery/

38.31 or 32 or 33 or 34 or 35 or 36 or 37

39.30 and 38

\section{CENTRAL}

\#1 crohn* or "inflammatory bowel disease" or IBD

\#2 anti-metabolite* or antimetabolite*

\#3 6-mercaptopurine or mercaptopurine or $6-\mathrm{MP}$ or $6 \mathrm{MP}$

\#4 AZA or azathioprine

\#5 \#2 or \#3 or \#4

$\# 6 \# 1$ and \#5

$\# 7$ surgery or surgic* or post-surgical or post-surgery or postoperative or post-operative or resection or operation \#8 \#6 and \#7

SR-IBD

Azathioprine and 6-mercaptopurine for maintenance of surgically-induced remission in Crohn's disease (Review)

Copyright $\odot 2014$ The Cochrane Collaboration. Published by John Wiley \& Sons, Ltd. 


\section{WHAT'S NEW}

Last assessed as up-to-date: 30 April 2014.

\begin{tabular}{l|l|l} 
Date & Event & Description \\
\hline 24 September 2014 & Amended & Correction of minor typo \\
\hline
\end{tabular}

\section{CONTRIBUTIONSOFAUTHORS}

Morris Gordon led the review and was involved in all phases. Kelly Taylor co-searched, led the write up of the results and discussion. Anthony Akobeng and Adrian Thomas commented on and supported all stages of the review.

\section{DECLARATIONSOF INTEREST}

Morris Gordon has received travel grants from Warner Chilcott Pharmaceuticals, Cassen Fleet, Vifor Pharma, Ferring Pharmaceuticals and Abbott to attend Digestive Disease Week (DDW), and other scientific meetings to present results of systematic reviews. He has also acted a clinical editor for Danone nutrition, and has received lecture fees from Warner Chilcott Pharmaceuticals for a presentation at DDW. These companies had no involvement in the review process or write up of this or any previous works.

The other authors have no known interests to declare.

\section{DIFFERENCES BETWEEN PROTOCOL AND REVIEW}

The following sensitivity analyses were planned but not carried out due to lack of data and small number of studies:

a. only including patients' whose outcome was known i.e. number of patients who completed the study used as denominator;

b. allocation concealment;

c. dose of AZA/6-MP; and

d. concurrent medications (5-aminosalicylic acid and other concurrent immunosuppressants such as methotrexate, cyclosporine, mycophenolate mofetil, infliximab, or adalimumab). 
I NDEX TERMS

\section{Medical Subject Headings (MeSH)}

6-Mercaptopurine [* therapeutic use]; Anti-Inflammatory Agents, Non-Steroidal [therapeutic use]; Antibodies, Monoclonal [therapeutic use]; Antibodies, Monoclonal, Humanized [therapeutic use]; Azathioprine [*therapeutic use]; Crohn Disease [*drug therapy; prevention $\&$ control; surgery]; Immunosuppressive Agents [ ${ }^{*}$ therapeutic use]; Maintenance Chemotherapy [ ${ }^{*}$ methods]; Mesalamine [therapeutic use]; Randomized Controlled Trials as Topic; Remission Induction [methods]; Secondary Prevention

\section{MeSH check words}

Humans 